\title{
Mechanical behavior of composite materials for marine applications - an experimental and computational approach
}

\author{
${ }^{1}$ National Institute of Ocean Technology, Deep Sea Technologies (Mining), Velachery-Tambaram Road, Narayanapuram, Pal- \\ likaranai, Chennai, India, E-mail: kathavate_vaibhav@rediffmail.com. http://orcid.org/o0o0-0001-9332-9320. \\ ${ }^{2}$ National Institute of Ocean Technology, Deep Sea Technologies (Mining), Velachery-Tambaram Road, Narayanapuram, Pal- \\ likaranai Chennai, India \\ ${ }^{3}$ College of Engineering, Anna University, Department of Chemistry, Anna University, Guindy Chennai, India
}

\begin{abstract}
:
The maturity of sophisticated numerical tools for predicting damage in composite materials has become a priority research area in aero- and underwater structures. This paper proposes a modeling approach to endeavor achieving high fidelity of mechanical behavior of composite materials subjected to high pressure applications. The strategy begins with numerical methods to design an alternative material for high pressure applications and to build a ladder with experimental observations when these composites are deployed for 600 bar pressure which take into account the relevant deformation, effective estimation of mechanical properties and failure mechanisms at different length scales. Coupon-shaped specimens with different hardener-epoxy ratios were manufactured to investigate the uniaxial tensile performance and the morphological studies were carried out in order to have a picture regarding the delamination and debonding behavior of the aforementioned composites. The further scope of this work involves a review of some notable micromechanic models and to establish the state-of-art together with insights for future development. Analytical models based on the mechanics of materials (MOM) approach and Mori-Tanaka (M-T) methods are shown to estimate the elastic response of composite materials. An attempt has been made to validate these finite-element predictions with experimental observations in order to secure the capability of a numerical framework. The outcome of our study also assures that these composites can be used in advanced structural applications under different conditions.
\end{abstract}

Keywords: damage mechanics, mechanical behavior, micromechanics, polymer composites

DOI: $10.1515 / j m b m-2018-0003$

\section{Introduction}

Owing to their significant mechanical and physical properties, carbon fiber reinforced polymer matrix composites have emerged as one of the most promising materials to tailor the effective elastic properties in high pressure applications [1], [2], [3]. Due to these outstanding properties, it is believed that an increase in weight percentage of fiber can considerably improve the thermomechanical and thermoelastic response of composites [4]. A significant number of experiments and numerical studies have been conducted to study the effective elastic properties of carbon fiber reinforced polymer composites.

Good progress has been made in the micromechanics of composite materials over the last three decades. This has been partly motivated by the need to reduce the high development costs currently incurred in the advancement of new generation military transport aircraft and underwater vehicles which make extensive use of carbon-fiber materials in their primary structure. One way to achieve this is to replace experimental testing with simulation. Micromechanics of composites come into the picture for the effective estimation of properties of constituents; some of which are thermoelastic coefficients and thermal conductivities. The finite-element method has been widely adopted for the modeling of in-plane damage and delamination, achieved using continuum damage mechanics and fracture mechanics [5], [6].

Over the last two decades there have been innumerous micromechanical models developed to predict the macroscopic behavior of polymer composite materials typically reinforced with carbon or glass fibers [7]. The basic assumption behind entire fraternity of micromechanical models is: the matrix, fibers and the interface are assumed to be continuous materials and constitutive equations are derived based on continuum mechanics. It 
can be noted that, though a great panorama of research has been discussed, the production of these unidirectional composites is still a challenging task. The earliest work in the context of micromechanics was started by Voigt [8] and Reuss [9] and was highly appreciated. It was concluded by Voigt that, the state of strains is constant in the constituents under the application of a load. On the contrary, Reuss proposed, stresses are constant in the constituents. Interestingly, the theories of Voigt and Reuss were effectively used by Hill [10] to derive upper and lower bounds of elastic properties of composites. Motivated by Hill's work, Hashin and Shtrikman [11] devoted their entire efforts to the effective estimation of upper and lower bounds for elastic properties of quasi-isotropic and quasi-homogeneous materials with a special focus on the variational approach.

In metals, the stage of gradual and invisible deterioration is nearly about their complete span of their operational life. There is no significant reduction in overall stiffness during the entire fatigue process. On the other hand, the deterioration in composites due to fatigue is observed by the formation of multitudes of microcracks and debonding [12]. It was quickly acknowledged from the very first experiment on advanced composite structures that fatigue failure mechanisms for these materials are more complicated than for a metal counterpart [13]. Further, it was reported that most of the failure process in deformation can be attributed to void nucleation in fiber-reinforced plastic composites and shear band formation in metallic glasses [14]. This was strongly supported by the simulation of failure based on the micromechanics approach. Tenchev and Falzon [6] have reported on recent trends in FEM modeling of delamination having special emphasis on the development of cohesive interfacial elements. Over time numerous mesh free methods for fracture and crack growth have been developed and it was found that cohesive zone modeling is one of the most widely used techniques for modeling crack and delamination propagation [15].

The damage mechanism due to impact loading can be shown in four different categories: delamination, matrix cracking, fiber breakage and total perforation. It is very important to understand the unknown fact, such as, failure criteria, debonding and interfacial delamination about degradation of the initial properties, the establishment of criteria for local failure in individual lamina and various failure models. The aforementioned complexities are beyond anyone's control from the quantitative frame of reference and thus need to be shown in the form constitutive equations [16]. The work carried out by Hashin and Rotem [17] and Awerbuch and Hahn [18] addressed a lot of fatigue-test data interpreted by using empirical relations for glass-epoxy and carbonepoxy materials. As a counterpart, analytical models proposed for unidirectional composites under fatigue rationalized the cycle-fatigue failure in laminates [19].

On a solemn note, the evaluation of macroscopic elastic properties of two phase composites was addressed by Hill [20], who stated that there exists a simple universal relation between overall elastic moduli of composites when subjected to transversely isotropic phases and have no such concurrence with volume fraction. The thermoelastic properties of unidirectional (UD) fiber reinforced composites were well estimated using the mechanics of materials (MOM) approach as opposed to the discrete element and semi-empirical methods [21]. On the other hand, the Mori-Tanaka (M-T) method proved successful for the effective estimation of elastic properties under the transverse isotropic mode. A further method of cells approach can be viewed as an alternative for the assessment of the thermoelastic properties [22]. Apart from the abovementioned models, there are innumerous micromechanical models that have been developed for the evaluation of overall properties of composite materials: these typically include the two- and three-phase MOM approach [23], [24], [25], the multiphase M-T method [26] and shear lag and pull out models [27]. Self-consistent mechanics of composites for isotropic dispersion was proposed by Hill [28] and drew a solution for auxiliary elastic problems having uniformly loaded infinite mass containing ellipsoidal inhomogeneity.

Various studies have reported the use of composite technology in aircraft and by the 1950s fiber reinforced polymer composites were being explored in the field of marine structures [29], [30]. Among them glass reinforced polymer laminates have been used for many years in the fabrication of a wide variety of subsea structures. The most simplified and versatile beauty of using E glass fiber for underwater applications is its nonconductive nature and such that it could be used as an insulator to prevent and monitor marine corrosion, but under certain conditions of exposure, glass fiber may be attacked by moisture as it is sensitive to alkaline environments [31], [32]. The underwater environment is complex as it involves combinations of many perturbations such as wave currents, temperature and hydrostatic pressure. According to past studies most of the failure in subsea structures takes place due large amounts of hydrostatic pressure. Hydrostatic pressure $P$ in MPa is directly proportional to the depth $H$ in meters and could be proposed by following empirical equation [33]

$$
P=0.0101 H+\left(0.05 * 10^{-6}\right) H^{2} .
$$

Several studies had shown that the composites lose their tensile stiffness and strength progressively with water absorption and that the loss is proportional to apparent weight gain [34]. Chow et al. [35] investigated a fiber reinforced polypropylene composite specimen with hot water immersion at $90^{\circ} \mathrm{C}$. Finally, it revealed that loss in tensile modulus and strength was more for longer immersion time. 
Using this framework, FRP composites with various volume fractions of epoxy and fiber were manufactured using the hand layup process and were subsequently investigated for mechanical characteristics and strengthening effectiveness. They were produced as coupon-shaped specimens for uniaxial tensile response. It is of great interest to understand the behavioral mechanism of stiffness degradation in order to avoid redundancy and overdesign, therefore, a micromechanical model that accounts for the progressive damage is also proposed in the current endeavor.

Computational investigations reported by various studies concluded that all the aforementioned methods vary from established micromechanics techniques to prolonged intricate cases. The purpose of our study was to propose the multiplicity of micromechanical models with a special focus on elastic response of composites. Further study provides short and snappy briefs out of quick and insightful predictions of mechanical behavior under external pressure. The micromechanical field equations are presented owing to an ad hoc Eshelby tensor. To promote our understandings of composite materials for further high pressure applications, it is useful to develop the models for the effective estimations of properties of such materials.

\subsection{Bottom-up multiscale modeling strategy for composites}

There is a growing need in the engineering community to predict the mechanical behavior of composites using refined simulations. The standard strategy to tackle this problem starts from a numerical analysis using the finite-element method. This initial evaluation identifies hot spots in which damage is likely to occur and then these regions are further tailored for refined analysis. Non-linear constitutive and damage models along with phenomenological models are taken into account for predicting material behavior. The simplified beauty of these models is they have certain parameters whose values are reproducible and as a result there is a huge cost saving on experiments and testing.

Apart from the previously mentioned strategy, a new hierarchical approach has being under consideration to carry out virtual tests of composite materials. The current hypothesis for this said method is based on composite laminates which are obtained by stacking individual plies with various fiber orientations. The three different entities viz. laminate, ply and component whose mechanical behavior is rendered by length scales; fiber diameter, thickness of ply and laminate. It was reported by Llorca et al. [14] that fiber diameter varies from 5 to $10 \mu \mathrm{m}$ while ply thickness plays a vital role as it ranges typically from 100 to $300 \mu \mathrm{m}$ followed by standard laminate which has thickness of few $\mathrm{mm}$. This premise gives rise to the separation of length scale models confirming properties of one smaller entity alone (say ply) and thus by securing it to a relevant length scale for subsequent computation of properties of a larger entity (e.g. laminate). Thus, it can be concurred that multiscale modeling is governed by the transfer of information between different length scales instead of coupling different simulation techniques.

In composites, the interaction between the fiber and the matrix is at the microscopic level, but the mechanical responses are governed at the macroscopic level. Molecular dynamic simulations are the effective tool to study nanoscale phenomenon while the behavior at the macroscopic level could be conveniently studied with continuum mechanics. It is very important that macroscopic responses of fiber reinforced composites can be simulated using continuum mechanics. The representative volume element (RVE) or representative area element (RAE) have random distribution of reinforced carbon fibers that can be attributed to Eshelby's equivalent tensor.

The simplicity of Eshelby's tensor lies in the prediction of full multi-axial properties and responses of heterogeneous materials, which are often difficult to measure experimentally. In previous studies, effective mechanical properties of composites were evaluated using Eshelby's approach [36], [37], [38], [39], [40], [41], [42]. In the context of CNT reinforced composites, work carried out by Barai and Weng [43] is highly recognized and focuses on a two-scale micromechanics model to investigate the influence of CNT agglomeration upon the elastoplastic behavior of composites.

\section{Experimental}

\subsection{Materials and specimens}

The composite used in this study was a unidirectional randomly oriented E-glass roving fiber in an epoxy resin matrix. The elastic properties of epoxy resin are $E_{m}=1.5 \mathrm{GPa}, \mu_{m}=0.3$ and that of E-glass fiber are $E_{g}=73$ $\mathrm{GPa}, \mu_{g}=0.2$. The resin used for specimen preparation was an epoxy RENLAM LY 554 and its corresponding hardener was ARADUR HY 951. Curing of the laminate was performed under vacuum assisted by external 
pressure of 5 bar. The curing cycle was carried out in two stages; the first stage involves heating up to $100^{\circ} \mathrm{C}$ followed by $30 \mathrm{~min}$ of dwell time and this was succeeded by heating up to $180^{\circ} \mathrm{C}$ and dwell time of $60 \mathrm{~min}$.

Owing to the marginal reduction in production cost and time in the manufacturing process the hand layup technique was used for fabricating the composite specimens. Laminates were left to cure under standard atmospheric conditions. Three different variations were made. In each case the thickness of composite was increased by one layer of mat approximately $0.85 \mathrm{~mm}$ thick.

\subsection{Tensile test and pressure test}

For the effective estimation of mechanical properties, a series of tensile tests were conducted as per ASTM D638 course of action. A quasi-static load tension load was applied using a universal tensile testing machine (Zwick Inc., Kennesaw, USA). Tensile test coupons were cut from carbon fiber laminate (Figure 1). Details of the test methodology and relevant information can be extracted from ASTM D638 [44]. Tests were performed under the displacement-controlled mode of $3 \mathrm{~mm} / \mathrm{min}$.

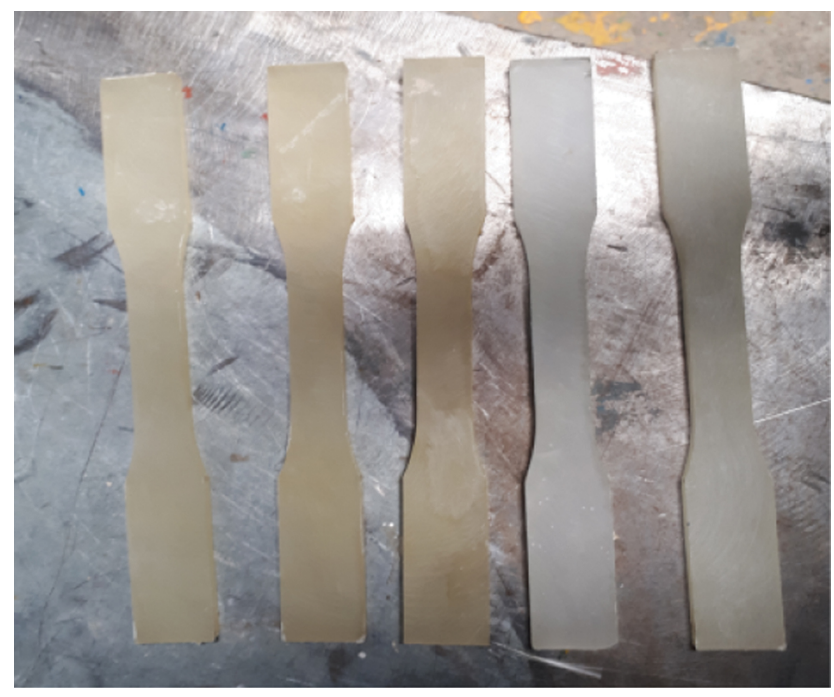

Figure 1: Tensile test specimens as per the ASTM D638 standard.

Further study was carried out by pressurizing samples at 600 bar. This pressurization of the specimen was carried out artificially in a large cylindrical chamber which had water and an anticorrosive fluid as a medium. The sole aim of this test was to show clear cut evidence of a behavioral change in the tensile strength of these composites and the extent of water absorption.

\subsection{Characterization studies}

Characterization and morphological studies of fabricated composites with both pressurized and unpressurized specimens were performed using scanning electron microscopy (SEM) to study the fractured surfaces of the tensile test specimen. A Hitachi S-3400 N Scanning Electron Microscope was used to carry out the morphological studies and specimens were sputter coated in order to make them non-conductive.

\subsection{FE and progressive damage analysis}

An FE model of a coupon-shaped specimen was created and implemented using the ANSYS package version 18.2 for the effective evaluation of damage parameters by comparing experimental and predicted uniaxial tensile response. Furthermore, the same model was implemented for the mechanical response of the composite. The following constituent properties were adopted: for the polymer matrix $E_{m}=1.3 \mathrm{GPa}, \mu_{m}=0.3$ and for that of E-glass fiber $E_{f}=102 \mathrm{GPa}, \mu_{f}=0.2$. A series of numerical tests were carried out with different combinations of lay ups and various damage models. Further constitutive equations were implemented. A coupon-shaped specimen was modeled (Figure 2) and the necessary boundary conditions (one end to be fixed while other to be arrested in the $x$ direction) were applied. Table 1. reveals the date required for finite-element analysis. A shell 63 element with a plane strain condition was deployed for the analysis. Local mesh (L-mesh) refinement was 
done by concentrating on edges and whole area was refined up to two maximums till the rate of convergence was obtained.

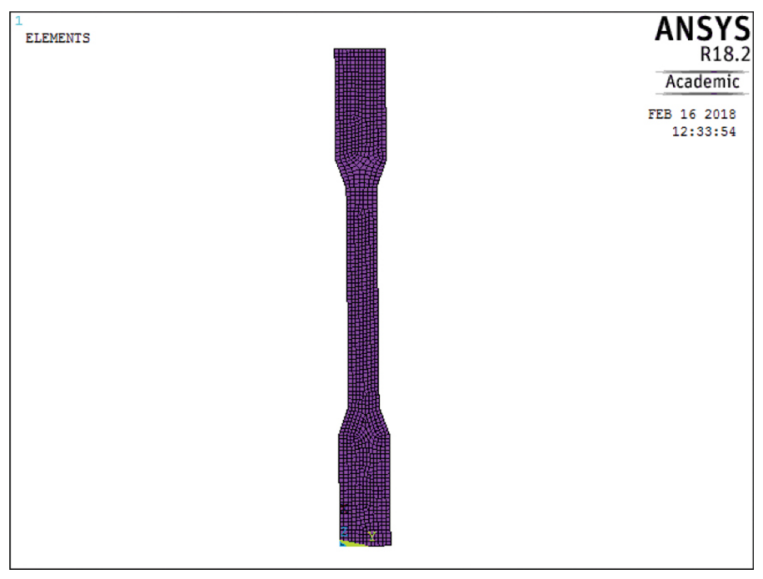

Figure 2: FE model and meshing in a coupon-shaped tensile test specimen (as per ASTM D638).

Table 1: FE model elements and mesh details.

\begin{tabular}{llllll}
\hline Material & Element & Meshing type & Mesh size (ndiv) & Total nodes & Total elements \\
\hline E-glass fiber & Shell 63 (plane & Quadrilateral & Along width $=$ & 1439 & 1298 \\
composite & strain) & Free & 12.5 & & \\
& & Along length $=$ & & \\
& & 55 & & \\
\hline
\end{tabular}

In addition to the tensile test simulation through ANSYS parametric language, progressive damage analysis was carried using the ACP (Pre) and ACP (Post) tools. Figure 3 reveals in the model for progressive damage analysis using ACP (Pre) tool. The progressive damage plots reveal the progressive damage results. Detailed information about the model is given in Table 2.

Table 2: Progressive damage model details.

\begin{tabular}{ll}
\hline Material & E-glass fiber composite \\
\hline Damage initiation criteria & Maximum stress \\
Tensile fiber stiffness reduction & 0.75 \\
Tensile matrix stiffness reduction & 0.75 \\
Element size & $1.5 \mathrm{~mm}$ \\
Meshing type & Quadrilateral free \\
Total nodes & 1752 \\
Total elements & 1639 \\
Solver time & $40 \mathrm{~min}$ \\
\hline
\end{tabular}

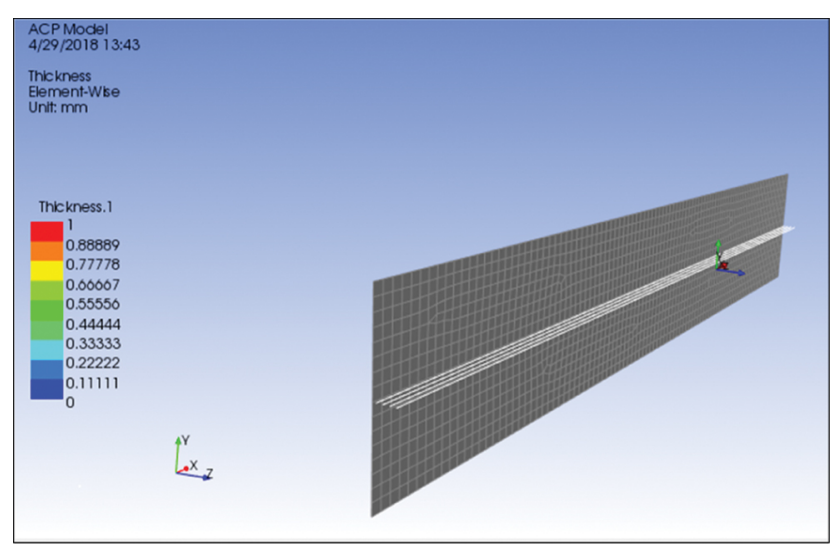


Figure 3: Progressive damage model of epoxy E-glass fiber composite with thickness of ply $1 \mathrm{~mm}$ (four layers).

\section{Results and discussion}

\subsection{Gel time study}

Gel time was carried out by heating the epoxy and observing when it started to become stringy or more viscous though not being fully cured. In this present framework, three resin-hardener ratios 100:8 (Sample 1), 100:10 (Sample 2) and 100:12 (Sample 3) were chosen in order to facilitate faster curing times and the maximum temperature range. Both the compounds were measured by volume and poured into the mold and stirred until even dispersion was observed (Figure 4).

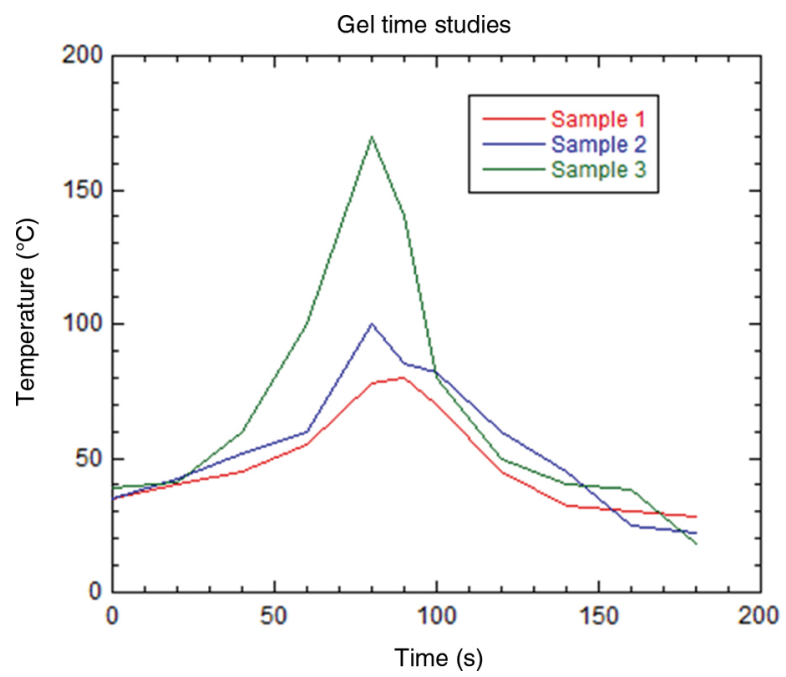

Figure 4: Gel time studies observations for (A) sample 1 (100:8), (B) sample 2 (100:10) and (C) Sample 3 (100:12).

It was observed that there was a shift in time-temperature distribution curve as a quantity of hardener was increased. So it could be inferred from the gel-time studies mentioned that the time required to settle at the peak temperature showed a marginal decrease. Furthermore, it was also found there was increase in peek temperature as the mixing ratio goes on increasing. The slope of the graph observed with mixing ratio 100:12 was steeper as compared to other two. Increased quantity of hardener is anticipated to have a decrease in settling time and an increase in peak temperature. It is noteworthy that there was decrease in strength as the quantity of hardener was increased in sample 3 and this can be attributed to further discussions made on tensile test behavior of these composite in the tension test.

\subsection{Tensile test}

The tensile test of both pressurized and unpressurized specimens was carried out in accordance with ASTM D638's course of action (Figure 5). All three samples were deployed for 600 bar hydrostatic pressure in a hyperbaric chamber followed by the tensile test. It is noteworthy to mention that unpressurized sample 3 had a mixing ratio of 100:12 and failed at the lower load and this may have been due to the increased hardness which makes the resin brittle, while sample 2 had mixing ratio of 100:10 and failed at a higher breaking load and was anticipated to offer a resilience which it showed (Figure 6). 


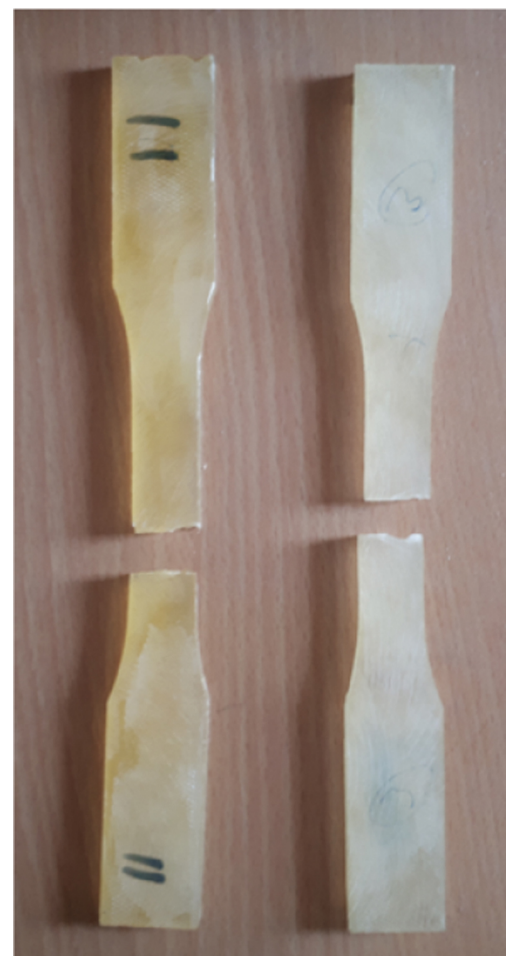

Figure 5: Specimen after tensile testing.

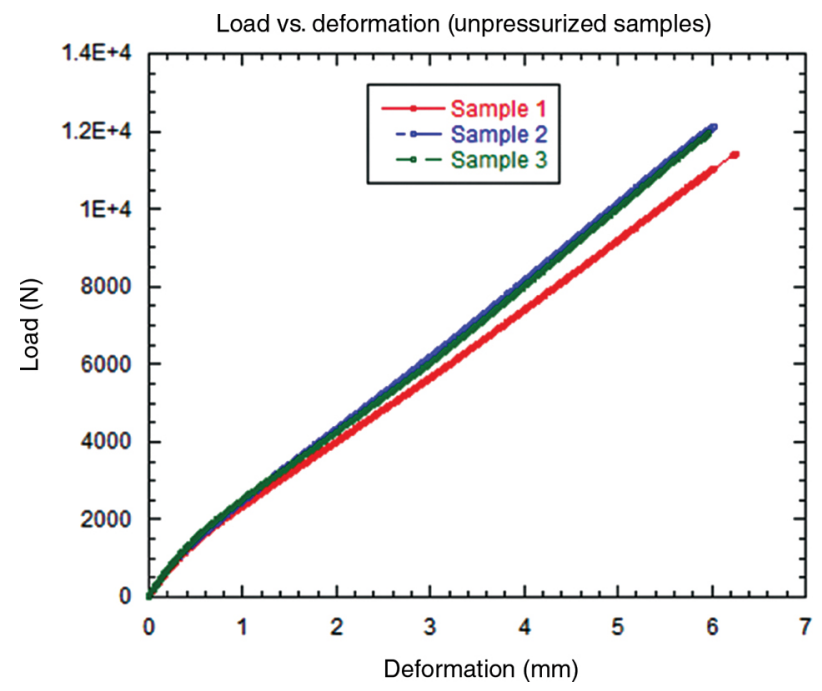

Figure 6: Load vs. deformation behavior of unpressurized composite specimens (A) sample 1 (100:8), (B) sample 2 (100:10) and (C) sample 3 (100:12).

Pressurized specimens up to 600 bar were deployed for the tensile test in order to evaluate the behavioral change of the composites. It is worth mentioning here, in the current framework the tensile strength of these materials was increased as a function of hydrostatic pressure and higher breaking loads were observed during the tensile testing (Figure 7). This proposed hypothesis conforms well with the previous work carried out by Davis et al. [33] and Davies and Rajpakshe [66]. The tensile test data for both pressurized and unpressurized samples is summarized in Table 3. However, this current postulate is not adequate to differentiate between the behavioral change in composite materials and SEM studies may be useful in this regard therefore, in the current framework the next stage would be characterization studies in conjunction with tensile testing. 


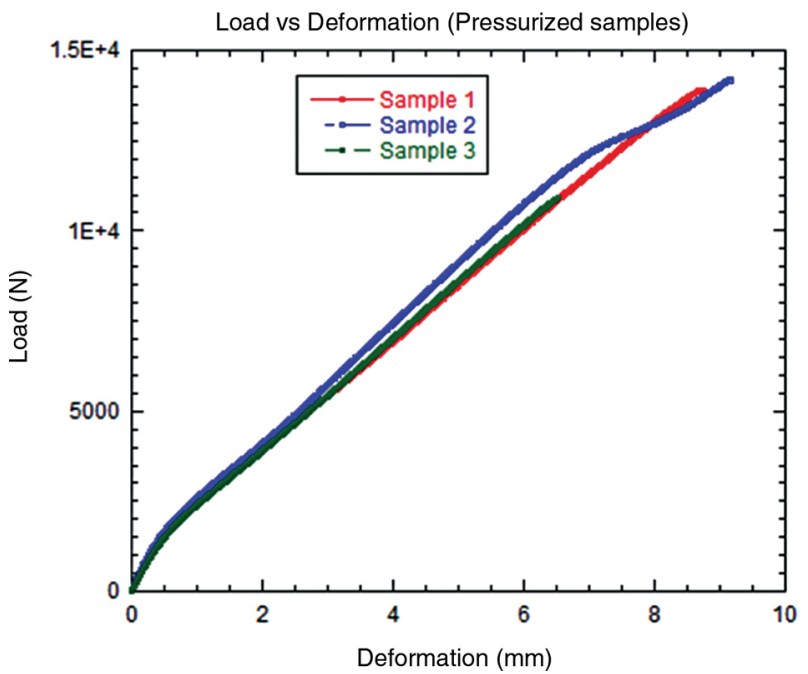

Figure 7: Load vs. deformation behavior of pressurized composite specimens (A) sample 1 (100:8), (B) sample 2 (100:10) and (C) sample 3 (100:12).

Table 3: Tensile test data for unpressurized and pressurized samples.

\begin{tabular}{lrrrrrrrr}
\hline Properties & \multicolumn{2}{c}{ Breaking load (n) } & & \multicolumn{2}{c}{ Deformation (mm) } & & \multicolumn{2}{c}{ Tensile strength (MPa) } \\
\cline { 2 - 3 } & Unpressurized & Pressurized & & Unpressurized & Pressurized & & Unpressurized & Pressurized \\
\hline Sample 1 (100:8) & 11961 & 13815 & 3.330 & 3.442 & & 1180.3 & 1310.1 \\
Sample 2 (100:10) & 12113 & 14130 & & 3.178 & 4.661 & & 1301.7 & 1640.6 \\
Sample 3 (100:12) & 10900 & 11413 & 3.146 & 4.832 & & 978.5 & 1246.5 \\
\hline
\end{tabular}

\subsection{Characterization studies}

In order to quantify the internal damage, samples with varying degrees of damage were analyzed using SEM. It is evident from the Figure 8A that there was a greater extent of fiber pull out and delamination observed the unpressurized sample. This was probably due to improper interaction between the fiber and the resin which may give birth to internal debonding in ambient conditions. However, the present study is centered only towards understanding the morphological behavior of these composites at higher pressure in order to certify them for marine applications.
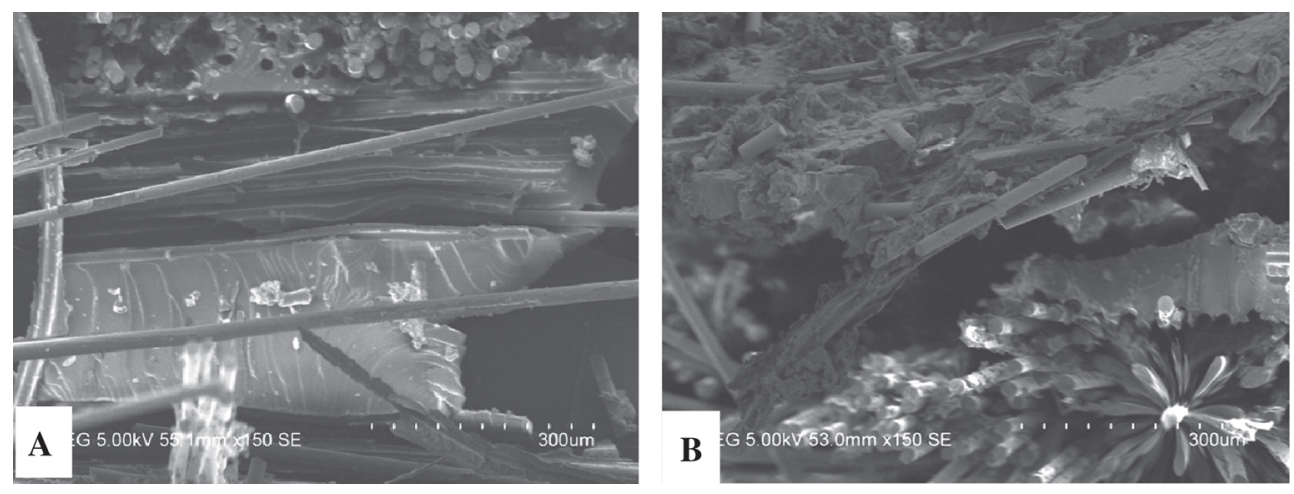

Figure 8: SEM micrographs of (A) an unpressurized sample, (B) a pressurized sample (600 bar) after tensile testing debonding and an improper fiber-matrix interface.

It can be chance that external pressure may help the matrix to hold the fiber firmly at 600 bar pressure which in turn reduces the degree of delamination to some extent (Figure 8B). There was less degrees of fiber pull out which may lead to increase in mechanical properties of the material which is in agreement with tensile test results.

However, in the current study it was observed that hydrostatic pressure was proven to be beneficial for aforementioned composite materials and it was anticipated to have an adequate degree of compactness. It can 
be also inferred from the study here that mechanical properties no longer remain constant, instead they showed a great variation as a function of hydrostatic pressure. Currently the authors are working on the extent of water absorption to envisage the effect of apparent weight gain in for the pressurized FRP composite materials in order to qualify them for subsea application. Hence, the evaluation of mechanical properties after water absorption is indeed a requirement.

\subsection{Computational micromechanics}

Here, an attempt has been made to form constitutive equations considering various models. Initially it is assumed that reinforcement of fiber is grimed over lamina (a composite assumed to be one single component having orthotropic properties) and the fiber-matrix combination is assumed to be a single material. Hook's law in tensorial form can be presented as,

$$
\left\{\begin{array}{l}
\varepsilon_{11} \\
\varepsilon_{22} \\
\varepsilon_{33} \\
\gamma_{23} \\
\gamma_{13} \\
\gamma_{12}
\end{array}\right\}=\left[\begin{array}{cccccc}
\frac{1}{E_{E_{2}}} & -\frac{\mu_{12}}{E_{1}} & -\frac{\mu_{13}}{E_{1}} & 0 & 0 & 0 \\
-\frac{\mu_{21}}{E_{2}} & \frac{1}{E_{2}} & -\frac{\mu_{23}}{E_{2}} & 0 & 0 & 0 \\
-\frac{\mu_{31}}{E_{3}} & -\frac{\mu_{32}}{E_{3}} & \frac{1}{E_{3}} & 0 & 0 & 0 \\
0 & 0 & 0 & \frac{1}{G_{32}} & 0 & 0 \\
0 & 0 & 0 & 0 & \frac{1}{G_{13}} & 0 \\
0 & 0 & 0 & 0 & 0 & \frac{1}{G_{12}}
\end{array}\right]\left\{\begin{array}{l}
\sigma_{11} \\
\sigma_{22} \\
\sigma_{33} \\
\tau_{23} \\
\tau_{13} \\
\tau_{12}
\end{array}\right\} .
$$

where, $E_{1}, E_{2}$ and $E_{3}$ are elastic modulus along the 1-3 direction and $G_{12}, G_{32}$ and $G_{13}$ are shear modulus, also $\varepsilon_{11}, \varepsilon_{22}$ and $\varepsilon_{33}$ are normal strains and $\varepsilon_{12}, \varepsilon_{13}$ and $\varepsilon_{23}$ in the plane and transverse shear strains, respectively.

It is worth mentioning here that the elastic constants in equation 1 are not all independent. This is the case when the symmetric matrix comes into the picture. When composites are deployed for heating the load, deformation takes place, then the thermal stress-strain relation can be given by equation 2 .

$$
\left\{\begin{array}{c}
\varepsilon_{11}-\alpha_{1} \Delta T \\
\varepsilon_{22}-\alpha_{2} \Delta T \\
\varepsilon_{33}-\alpha_{3} \Delta T \\
\varepsilon_{23} \\
\varepsilon_{13} \\
\varepsilon_{12}
\end{array}\right\}=\left[\begin{array}{cccccc}
\frac{1}{E_{1}} & -\frac{\mu_{12}}{E_{1}} & -\frac{\mu_{13}}{E_{1}} & 0 & 0 & 0 \\
-\frac{\mu_{21}}{E_{2}} & \frac{1}{E_{2}} & -\frac{\mu_{23}}{E_{2}} & 0 & 0 & 0 \\
-\frac{\mu_{31}}{E_{3}} & -\frac{\mu_{32}}{E_{3}} & \frac{1}{E_{3}} & 0 & 0 & 0 \\
0 & 0 & 0 & \frac{1}{G_{32}} & 0 & 0 \\
0 & 0 & 0 & 0 & \frac{1}{G_{13}} & 0 \\
0 & 0 & 0 & 0 & 0 & \frac{1}{G_{12}}
\end{array}\right]\left\{\begin{array}{c}
\sigma_{11} \\
\sigma_{22} \\
\sigma_{33} \\
\sigma_{23} \\
\sigma_{13} \\
\sigma_{12}
\end{array}\right\}
$$

where, $\Delta \mathrm{T}$ is the temperature change across the material and $\alpha_{1}, \alpha_{2}$ and $\alpha_{3}$ are the coefficients of thermal expansion. The sole aim of this micromechanics-based model is to predict overall average properties of the composites. So, in generalized notation equation 1 can be written as,

$$
\{\varepsilon\}_{6 \times 1}=[Q]_{6 \times 6}\{\sigma\}_{6 \times 1}
$$

The prediction of elastic properties such as elastic modulus, shear modulus and Poisson's ratio are of great importance in any scientific MOM approach. It was found from the past literature that experimental results are not in line with the results obtained by the strength of the materials approach. Therefore, use of numerical techniques such as the finite-element method, the discrete-element method, the theory of elasticity and the variational approach are anticipated to offer only an approximate but optimal solution to these problems. It has been noticed that, the micromechanics approach is used to evaluate the elastic moduli or stiffness or compliance of the composite materials which is ultimately a function of the tensile modulus of fiber and matrix, Poisson's ratio and the volume fraction,

$$
C_{i j}=C_{i j}\left(E_{m}, V_{m}, \mu_{m}, E_{f}, V_{f}, \mu_{f}\right)
$$

The Halpin-Tsai [45] equation for the estimation of tensile modulus of a composite in the axial direction $\left(E_{1}\right)$ uses the generalized law of volume fraction and can be given by equation (5),

$$
E_{1}=E_{f} v_{f}+\left(1-v_{f}\right) E_{m}
$$


where, $E_{f}$ and $E_{m}$ are the tensile modulus of fiber and matrix, respectively, and $V_{f}$ and $V_{m}$ are the volume fraction of fiber and matrix, respectively. The apparent tensile modulus $\left(E_{2}\right)$ in transverse direction can be given by,

$$
E_{2}=\frac{E_{f} E_{m}}{v_{f} E_{f}+V_{m} E_{m}}
$$

The in-plane shear modulus $\left(G_{12}\right)$ can be determined by the MOM approach by presuming the shear stress developed in the fiber and the matrix are the same (but the shear deformations cannot be same).

$$
G_{12}=\frac{G_{f} G_{m}}{v_{f} G_{f}+V_{m} G_{m}}
$$

In the elastic regime, the homogenization theory is well-established, efficient and accurate, and anticipated to compute overall composite behavior. It can offer analytical solutions for the constitutive equations which are revealed in structural analysis codes for the mechanical response. Nevertheless, the situation involving strain localization and fracture is tiresome and the accuracy of the results is not always failsafe [46]. So, these aforementioned limitations could be overcome with the development of computational micromechanics. In addition, computational micromechanics are anticipated to offer significant advantages like complex nonlinear behavior (geometrical and material) for multiaxial stress states, which are often very difficult to prove experimentally.

A nucleation and growth of damage during simulation can be easily traced with the help of computational micromechanics. Owing to its history, it was first implemented to explore the effects of spatial distribution, shape deformation and the effect of volume fraction of composites [47].

In this current endeavor, damage is assumed to develop by the formation of a homogeneous distribution of microcracks and is regarded as damage variable ' $d$ '. The constitutive behavior can be given as

$$
\sigma=[1-d(\varepsilon)] E \varepsilon
$$

where $E$ is the elastic modulus and initially the response of material is elastic up to a strain $(d=0)$ where damage starts to grow until complete damage would occur $(d=1)$. This basis of the framework has been extended by different authors to evaluate the mechanical response of composites having a special focus on interplay of the failure mechanism [48], [49], [50], [51], [52], [53], [54], [55], [56], [57], [58]. The relationship between stress and strain can be given by a compliance tensor,

$$
\left[\begin{array}{l}
\varepsilon_{11} \\
\varepsilon_{22} \\
\varepsilon_{33} \\
\gamma_{13} \\
\gamma_{23} \\
\gamma_{12}
\end{array}\right]=\left[\begin{array}{cccccc}
\frac{1}{\left(1-d_{1}\right) E_{1}} & -\frac{\mu_{12}}{E_{1}} & -\frac{\mu_{13}}{E_{1}} & 0 & 0 & 0 \\
-\frac{\mu_{21}}{E_{2}} & \frac{1}{\left(1-d_{2}\right) E_{2}} & -\frac{\mu_{23}}{E_{2}} & 0 & 0 & 0 \\
-\frac{\mu_{31}}{E_{3}} & -\frac{\mu_{32}}{E_{3}} & \frac{1}{\left(1-d_{3}\right) E_{3}} & 0 & 0 & 0 \\
0 & 0 & 0 & \frac{1}{\left(1-d_{4}\right) G_{13}} & 0 & 0 \\
0 & 0 & 0 & 0 & \frac{1}{\left(1-d_{5}\right) G_{23}} & 0 \\
0 & 0 & 0 & 0 & 0 & \frac{1}{\left(1-d_{6}\right) G_{12}}
\end{array}\right]\left[\begin{array}{c}
\sigma_{11} \\
\sigma_{22} \\
\sigma_{33} \\
\tau_{13} \\
\tau_{23} \\
\tau_{12}
\end{array}\right]
$$

where index 1 stands for matrix direction, $E_{1}, E_{2}, E_{3}, G_{1}, G_{2}, G_{3}, \mu_{12}, \mu_{13}, \mu_{23}$ are nine independent constants of orthotropic ply having damage tensors,

$$
d=\left\{d_{1} d_{2} d_{3} d_{4} d_{5} d_{6}\right\}
$$

It was observed from previous studies that the dominant damage mechanisms are found in laminate plane, thus in this framework $d_{3}=d_{4}=d_{5}=0$ (assumed to be zero) and $d_{1}$ and $d_{2}$ would come into the picture when damage is associated with the parallel and perpendicular to the fiber direction. It is also noteworthy that, the damage parameter $d_{6}$ accounts for in-plane shear deformation. After substituting the values of damage parameters equation 9 can be re-written as,

$$
\left[\begin{array}{c}
\varepsilon_{11} \\
\varepsilon_{22} \\
\varepsilon_{33} \\
\gamma_{13} \\
\gamma_{23} \\
\gamma_{12}
\end{array}\right]=\left[\begin{array}{c}
\frac{1}{\left(1-d_{\left.\mu_{21}\right) E_{1}}\right.} \\
-\frac{\mu_{21}}{E_{2}} \\
-\frac{\mu_{31}}{E_{3}} \\
0 \\
0 \\
0
\end{array}\right.
$$$$
\begin{aligned}
& -\frac{\mu_{12}}{E_{1}} \\
& \frac{1}{\left(1-d_{2}\right) E_{2}} \\
& -\frac{\mu_{32}}{E_{3}} \\
& 0 \\
& 0 \\
& 0
\end{aligned}
$$

$$
\left.\begin{array}{cccc}
-\frac{\mu_{13}}{E_{1}} & 0 & 0 & 0 \\
-\frac{\mu_{23}}{E_{2}} & 0 & 0 & 0 \\
\frac{1}{\left(1-d_{3}\right) E_{3}} & 0 & 0 & 0 \\
0 & \frac{1}{G_{13}} & 0 & 0 \\
0 & 0 & \frac{1}{G_{23}} & 0 \\
0 & 0 & 0 & \frac{2}{G_{12}}
\end{array}\right]\left[\begin{array}{l}
\sigma_{11} \\
\sigma_{22} \\
\sigma_{33} \\
\tau_{13} \\
\tau_{23} \\
\tau_{12}
\end{array}\right]
$$


It is worth mentioning in this work that failure of the unidirectional fiber composites due to a specified state of stress is given by the Tsai [59] equation which was later modified by Hill [60] can be given from equation 12,

$$
A\left(\sigma_{11}-\sigma_{22}\right)^{2}+B\left(\sigma_{22}-\sigma_{33}\right)^{2}+C\left(\sigma_{33}-\sigma_{11}\right)^{2}+2 \mathrm{D}{\sigma_{12}}^{2}+2 \mathrm{D}{\sigma_{23}}^{2}+2 \mathrm{D}{\sigma_{31}}^{2}=1
$$

On a serious note, one can also neglect the effect of shear stresses and if only squares terms of normal stresses comes into the picture then this criteria holds good for isotropic tension of fiber composites.

The overall progressive damage in fiber and matrix status can be displayed indicating no damage $(\mathrm{d}=0)$, some damage $(0.10-0.66)$ and complete damage $(\mathrm{d}=1)$ (Figure 9A-C). Eventually, the damage variable gives an indication of stiffness reduction for the fiber and the matrix in tension and compression (Figure 9D). Figure 9F depicts in maximum failure criteria for the fiber- matrix interface. It can be inferred from Figure 9F-H that most of the damage was observed at fiber-matrix interface where the maximum displacement was applied. The total deformation observed in this process was $3 \mathrm{~mm}$. Furthermore, the damage variable scale goes from 0 (no damage, $0 \%$ stiffness reduction) to maximum stiffness reduction specified (0.75) (complete damage, 100\% stiffness reduction).
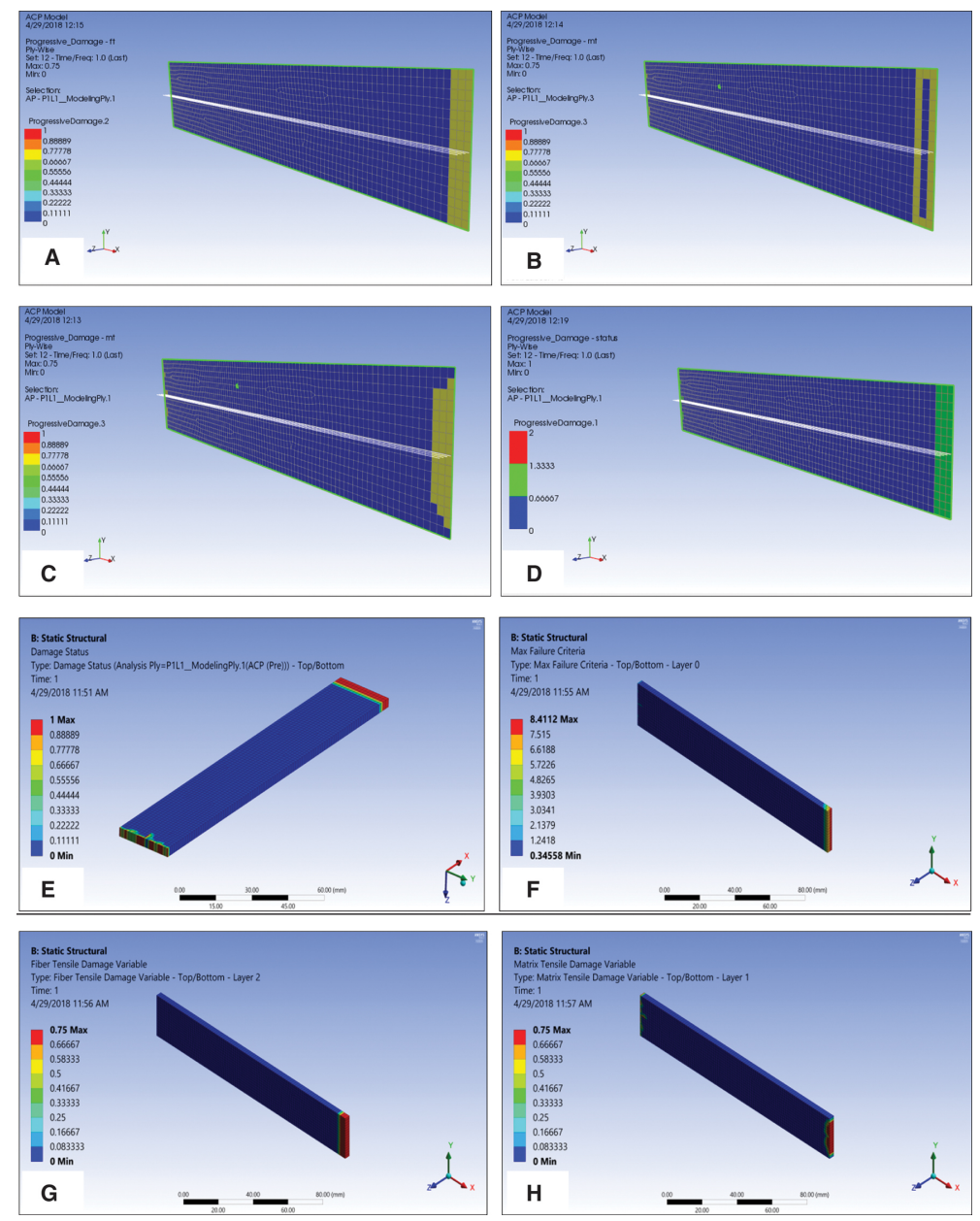

Figure 9: (A) Progressive damage for fiber layer, (B) Progressive damage for matrix layer 1, (C) Progressive damage for matrix layer 4, (D) Progressive damage status, (E) Damage status for fiber ply 1, (F) Maximum failure criteria, (G) Fiber tensile damage variable and $(\mathrm{H})$ Matrix tensile damage variable.

To evaluate the effective elastic properties of composite materials made of transversely isotropic constituents, one can use the MOM approach generalized by rule of mixture imposing iso-field conditions [61], [62], [63]. The simplified versatility of iso-field conditions is; normal strains in the fiber and the matrix are equal along the fiber direction and transverse stresses in the same phase are equal along perpendicular direction to the fiber length. In conclusion, perfect bonding between the fiber and the matrix should be satisfied by iso-field conditions in addition to law of volume fraction. The interfacial bonding between the fiber and the matrix can be expresses as, 


$$
\left[\begin{array}{c}
\varepsilon_{11} \\
\sigma_{22} \\
\sigma_{33} \\
2 \gamma_{23} \\
2 \gamma_{13} \\
2 \gamma_{12}
\end{array}\right]=\left[\begin{array}{c}
\varepsilon_{11}^{f} \\
\sigma_{22}^{f} \\
\sigma_{33}^{f} \\
2 \gamma_{23}^{f} \\
2 \gamma_{13}^{f} \\
2 \gamma_{12}^{f}
\end{array}\right]=\left[\begin{array}{c}
\varepsilon_{11}^{m} \\
\sigma_{22}^{m} \\
\sigma_{33}^{m} \\
2 \gamma_{23}^{m} \\
2 \gamma_{13}^{m} \\
2 \gamma_{12}^{m}
\end{array}\right]
$$

$$
\left[\begin{array}{l}
\sigma_{11} \\
\varepsilon_{22} \\
\varepsilon_{33} \\
\varepsilon_{23} \\
\varepsilon_{13} \\
\varepsilon_{12}
\end{array}\right]=V_{f}\left[\begin{array}{c}
\sigma_{11}^{f} \\
\varepsilon_{22}^{f} \\
\varepsilon_{33}^{f} \\
\varepsilon_{23}^{f} \\
\varepsilon_{13}^{f} \\
\varepsilon_{12}^{f}
\end{array}\right]+V_{m}\left[\begin{array}{c}
\sigma_{11}^{m} \\
\varepsilon_{22}^{m} \\
\varepsilon_{33}^{m} \\
\varepsilon_{23}^{m} \\
\varepsilon_{13}^{m} \\
\varepsilon_{12}^{m}
\end{array}\right]
$$

From the above equations 13 and 14, stress and strain vectors can be expressed as,

$$
\begin{aligned}
& \{\sigma\}=\left[Q_{1}\right]\left\{\varepsilon^{m}\right\}+\left[Q_{2}\right]\left\{\varepsilon^{f}\right\} \\
& \{\varepsilon\}=\left[V_{1}\right]\left\{\sigma^{m}\right\}+\left[V_{2}\right]\left\{\sigma^{f}\right\}
\end{aligned}
$$

Here,

$$
\left[Q_{1}\right]=\left[\begin{array}{cccccc}
\mu_{m} C_{11}^{m} & \mu_{m} C_{12}^{m} & \mu_{m} C_{12}^{m} & 0 & 0 & 0 \\
C_{12}^{m} & C_{11}^{m} & C_{12}^{m} & 0 & 0 & 0 \\
C_{12}^{m} & C_{12}^{m} & C_{11}^{m} & 0 & 0 & 0 \\
0 & 0 & 0 & C_{44}^{m} & 0 & 0 \\
0 & 0 & 0 & 0 & C_{44}^{m} & 0 \\
0 & 0 & 0 & 0 & 0 & C_{44}^{m}
\end{array}\right]
$$

$$
\begin{aligned}
{\left[Q_{2}\right] } & =\mu_{f}\left[\begin{array}{cccccc}
C_{11}^{f} & C_{12}^{f} & C_{12}^{f} & 0 & 0 & 0 \\
0 & 0 & 0 & 0 & 0 & 0 \\
0 & 0 & 0 & 0 & 0 & 0 \\
0 & 0 & 0 & 0 & 0 & 0 \\
0 & 0 & 0 & 0 & 0 & 0 \\
0 & 0 & 0 & 0 & 0 & 0
\end{array}\right] \\
{\left[V_{1}\right] } & =\left[\begin{array}{cccccc}
1 & 0 & 0 & 0 & 0 & 0 \\
0 & \mu_{m} & 0 & 0 & 0 & 0 \\
0 & 0 & \mu_{m} & 0 & 0 & 0 \\
0 & 0 & 0 & \mu_{m} & 0 & 0 \\
0 & 0 & 0 & 0 & \mu_{m} & 0 \\
0 & 0 & 0 & 0 & 0 & \mu_{m}
\end{array}\right] \\
{\left[V_{2}\right] } & =\left[\begin{array}{cccccc}
0 & 0 & 0 & 0 & 0 & 0 \\
0 & \mu_{f} & 0 & 0 & 0 & 0 \\
0 & 0 & \mu_{f} & 0 & 0 & 0 \\
0 & 0 & 0 & \mu_{f} & 0 & 0 \\
0 & 0 & 0 & 0 & \mu_{f} & 0 \\
0 & 0 & 0 & 0 & 0 & \mu_{f}
\end{array}\right]
\end{aligned}
$$

Furthermore, the relation between stress and strain in fiber and matrix phases can be given by, 


$$
\left\{\varepsilon^{f}\right\}\left[Q_{1}^{\prime}\right]-\left\{\varepsilon^{m}\right\}\left[Q_{2}^{\prime}\right]=0
$$

where,

$$
\begin{aligned}
& {\left[Q_{1}^{\prime}\right]=\left[\begin{array}{cccccc}
1 & C_{12}^{f} & C_{13}^{f} & 0 & 0 & 0 \\
0 & C_{22}^{f} & C_{23}^{f} & 0 & 0 & 0 \\
0 & 0 & C_{33}^{f} & 0 & 0 & 0 \\
0 & 0 & 0 & C_{44}^{f} & 0 & 0 \\
0 & 0 & 0 & 0 & C_{55}^{f} & 0 \\
0 & 0 & 0 & 0 & 0 & C_{66}^{f}
\end{array}\right]} \\
& {\left[Q_{2}^{\prime}\right]=\left[\begin{array}{cccccc}
1 & C_{12}^{m} & C_{12}^{m} & 0 & 0 & 0 \\
0 & C_{11}^{m} & C_{12}^{m} & 0 & 0 & 0 \\
0 & 0 & C_{11}^{m} & 0 & 0 & 0 \\
0 & 0 & 0 & C_{44}^{m} & 0 & 0 \\
0 & 0 & 0 & 0 & C_{44}^{m} & 0 \\
0 & 0 & 0 & 0 & 0 & C_{44}^{m}
\end{array}\right]}
\end{aligned}
$$

It was observed that strain vectors in equation 16 can be written in a combined form as a composite strain and following relation can be achieved,

$$
\{\sigma\}=[K]\{\varepsilon\}
$$

where, $[K]=\left[Q_{1}\right]\left[V_{3}\right]^{-1}+\left[Q_{2}\right]\left[V_{4}\right]^{-1}$

$$
\left[V_{3}\right]=\left[V_{1}\right]+\left[V_{2}\right]\left[Q_{2}^{\prime}\right]^{-1}\left[Q_{1}^{\prime}\right] \text { and }\left[V_{4}\right]=\left[V_{2}\right]+\left[V_{1}\right]\left[Q_{1}^{\prime}\right]^{-1}\left[Q_{2}^{\prime}\right]
$$

It is evident from the above exercise that this MOM approach is not adequate to understand the overall mechanical performance of the composite materials. So in a previous study [64] an attempt was made to realize the fiber-matrix interaction carrying out some surface treatment on the fibers before embedding them in matrix. At present, the authors are studying knitted E-glass fiber undergoing surface treatment (sizing) before impregnated in the matrix. Therefore, the future scope of this method lies in forming new constitutive equations based on the three-phase MOM approach.

Owing to the significance of the MOM approach in the evaluation of elastic response properties of composite materials, Mori and Tanaka [29] derived a model equivalent to Eshelby's tensor which projected the interaction among neighboring reinforcements along the fibers. The versatility of the M-T method lies in the effective estimation of the orthotropic elastic properties of the composite materials and due to the ease in operation it is deliberately preferred by most of the researchers over the mechanics of the materials approach. [64],

In the present framework, the effective compliance matrix for the composite materials is given by Benveniste

$$
[S]=\left[C^{m}\right]+\mu_{f}\left\{\left[C^{f}\right]-\left[C^{m}\right]\right\}\left[A_{1}\right]
$$

where, $\left[A_{1}\right]=[A]\left[\mu_{m}[I]+\mu_{f}\left[A_{1}\right]\right]^{-1}$ and $[A]=\left[[I]+[P]\left[C^{m}\right]^{-1}\left\{\left[C^{f}\right]-\left[C^{m}\right]\right\}\right]^{-1}$

Here in the current framework, $[P]$ is attributed as Eshelby's tensor and it can be tailored based on the properties of the matrix and the fiber. Equation 20 reveals the elements in a three-dimensional (3D) Eshelby tensor, it is also worth mentioning here that these elements in Eshelby's tensor are based on the geometry of the fiber.

$$
[P]=\left[\begin{array}{cccccc}
L_{1111} & L_{1122} & L_{1133} & 0 & 0 & 0 \\
L_{2211} & L_{2222} & L_{2233} & 0 & 0 & 0 \\
L_{3311} & L_{3322} & L_{3333} & 0 & 0 & 0 \\
0 & 0 & 0 & L_{2323} & 0 & 0 \\
0 & 0 & 0 & 0 & L_{1313} & 0 \\
0 & 0 & 0 & 0 & 0 & L_{1212}
\end{array}\right]
$$

The elements in the above matrix can be calculated as, 


$$
\begin{array}{cc}
L_{1111}=L_{1122}=L_{1133}=0 & L_{2222}=L_{3333}=\frac{1}{2\left(1-\mu^{m}\right)}\left\{\frac{3}{4}+\frac{\left(1-2 \mu^{m}\right)}{2}\right\} \\
L_{2211}=L_{3311}=\frac{1}{2\left(1-\mu^{m}\right)} & L_{2233}=L_{3322}=\frac{1}{2\left(1-\mu^{m}\right)}\left\{\frac{1}{4}-\frac{\left(1-2 \mu^{m}\right)}{2}\right\} \\
L_{2323}=\frac{1}{2\left(1-\mu^{m}\right)}\left\{\frac{1}{4}+\frac{\left(1-2 \mu^{m}\right)}{2}\right\} & L_{1313}=L_{1212}=\frac{1}{4}
\end{array}
$$

This aforementioned Eshelby's tensor [65] is for the 3D case while one can read the same tensor in the twodimensional (2D) case as,

$$
\left[P_{i j}\right]=\left[\begin{array}{ccc}
L_{1111} & L_{1122} & 0 \\
L_{2211} & L_{2222} & 0 \\
0 & 0 & 2 L_{1212}
\end{array}\right]
$$

Now by substituting Eshelby's tensor (equation 20) in the value of $[A]$ to get the M-T tensor,

$$
\left[A_{i j}\right]=\left[\begin{array}{cccccc}
A_{11} & A_{12} & A_{13} & 0 & 0 & 0 \\
A_{21} & A_{22} & A_{23} & 0 & 0 & 0 \\
A_{31} & A_{32} & A_{33} & 0 & 0 & 0 \\
0 & 0 & 0 & A_{44} & 0 & 0 \\
0 & 0 & 0 & 0 & A_{55} & 0 \\
0 & 0 & 0 & 0 & 0 & A_{66}
\end{array}\right]
$$

The elements in the above matrix can be given by,

$$
\begin{gathered}
{\left[A_{11}\right]=\frac{E^{m}}{E_{11}^{f}}\left[1+\frac{\mu^{m}\left[\mu^{m}-\mu_{12}^{f}\right]}{\left[1-\left(\mu^{m}\right)^{2}\right]}\right] \quad\left[A_{21}\right]=\frac{E^{m}}{E_{11}^{f}}\left[\frac{\left[\mu^{m}-\mu_{12}^{f}\right]}{2\left[1-\left(\mu^{m}\right)^{2}\right]}\right]=\left[A_{31}\right]} \\
{\left[A_{12}\right]=\frac{E^{m}}{E_{22}^{f}}\left[\frac{\mu^{m}\left[1-\mu_{23}^{f}\right]}{2\left[1-\left(\mu^{m}\right)^{2}\right]}-\frac{E^{m}}{E_{11}^{f}} \frac{\left[\mu_{12}^{f}\right]}{\left[1-\left(\mu^{m}\right)^{2}\right]}+\frac{\mu^{m}}{2\left[1-\mu^{m}\right]}\right]=\left[A_{13}\right]} \\
\left.A_{22}\right]=\frac{E^{m}}{E_{22}^{f}}\left[\frac{\left[\mu_{23}^{f}-3\right]}{8\left[\left(\mu^{m}\right)^{2}-1\right]}+\frac{E^{m}}{E_{12}^{f}} \frac{\left[\mu_{12}^{f} \mu^{m}\right]}{2\left[\left(\mu^{m}\right)^{2}-1\right]}+\frac{\left[\mu^{m}+1\right]\left[4 \mu^{m}-5\right]}{8\left[\left(\mu^{m}\right)^{2}-1\right]}\right]=\left[A_{33}\right] \\
{\left[A_{32}\right]=\frac{E^{m}}{E_{22}^{f}}\left[\frac{\left[3 \mu_{23}^{2}-1\right]}{8\left[\left(\mu^{m}\right)^{2}-1\right]}+\frac{E^{m}}{E_{11}^{f}} \frac{\left[\mu_{12}^{f} \mu^{m}\right]}{2\left[\left(\mu^{m}\right)^{2}-1\right]}+\frac{\left[\mu^{m}+1\right]\left[1-4 \mu^{m}\right]}{8\left[\left(\mu^{m}\right)^{2}-1\right]}\right]=\left[A_{23}\right]} \\
{\left[A_{44}\right]=\frac{1}{4\left[1-\mu^{m}\right]}\left[\frac{G^{m}}{G_{23}^{f}}+\left[3-4 \mu^{m}\right]\right]} \\
{\left[A_{55}\right]=\frac{G^{m}+G_{12}^{f}}{2 G_{12}^{f}}=\left[A_{66}\right]}
\end{gathered}
$$

From the above exercise one can achieve the 3D elastic properties of the composite laminae. However, in most applications, only 2D properties of the composite materials are necessary, therefore, a 2D compliance tensor can be used as a 3D counterpart. Eventually, a 2D M-T tensor derived from a 3D tensor can be given as,

$$
\left[A_{i j}\right]=\left[\begin{array}{ccc}
a_{11} & a_{12} & 0 \\
a_{21} & a_{22} & 0 \\
0 & 0 & a_{33}
\end{array}\right]
$$

Here, 


$$
\begin{aligned}
& {\left[a_{11}\right]=\left[\frac{E^{m}}{E_{11}^{f}} \frac{\left\{\mu^{m}\left[4\left(\mu_{12}^{f}-1\right) \mu^{m}-3 \mu_{12}^{f}-8\right]+8\right\}}{8\left(\mu^{m}-1\right)^{2}\left(\mu^{m}+1\right)}+\frac{\left(4 \mu^{m}-1\right)\left(\mu^{m}\right)^{2}}{8\left(\mu^{m}-1\right)^{2}\left(\mu^{m}+1\right)}\right]} \\
& {\left[a_{12}\right]=\left[\frac{E^{m}}{E_{11}^{f}} \frac{\left[\mu _ { 1 2 } ^ { f } \left[\left(\mu^{m}\left(\left(\mu^{m}+2\right)-2\right]\right.\right.\right.}{2\left(\mu^{m}-1\right)^{2}\left(\mu^{m}+1\right)}+\frac{E^{m}}{E_{22}^{f}} \frac{\mu^{m}\left(3-4 \mu^{m}\right)}{8\left(\mu^{m}-1\right)^{2}\left(\mu^{m}+1\right)}+\frac{\mu^{m}\left(5-4 \mu^{m}\left(\mu^{m}+1\right)\right)}{8\left(\mu^{m}-1\right)^{2}\left(\mu^{m}+1\right)}\right]} \\
& {\left[a_{21}\right]=\left[\frac{E^{m}}{E_{11}^{f}} \frac{\left[4\left(\mu_{12}^{f}+1\right) \mu^{m}-3 \mu_{12}^{f}-8\left(\mu^{m}\right)^{2}\right]+8}{8\left(\mu^{m}-1\right)^{2}\left(\mu^{m}+1\right)}+\frac{\left(\mu^{m}\right)\left(4 \mu^{m}-1\right)}{8\left(\mu^{m}-1\right)^{2}\left(\mu^{m}+1\right)}\right]} \\
& {\left[a_{22}\right]=\left[\frac{E^{m}}{E_{22}^{f}} \frac{\left(3-4 \mu^{m}\right)}{8\left(\mu^{m}-1\right)^{2}\left(\mu^{m}+1\right)}+\frac{E^{m}}{E_{11}^{f}} \frac{\left[\mu_{12}^{f} \mu^{m}\left(2 \mu^{m}-1\right)\right]}{2\left(\mu^{m}-1\right)^{2}\left(\mu^{m}+1\right)}+\frac{\left(5-4 \mu^{m}\left(\mu^{m}+1\right)\right)}{8\left(\mu^{m}-1\right)^{2}\left(\mu^{m}+1\right)}\right]} \\
& {\left[a_{33}\right]=\frac{\left[G^{m}+G_{12}^{f}\right]}{2 G_{12}^{f}}}
\end{aligned}
$$

In this section the results obtained for the elastic constants by various models are discussed. Equations presented in preceding sections were implemented in MATLAB for the estimation of elastic coefficients of the compliance matrix with variation in the fiber volume fraction. For ease of understanding, only those models which are well established and proven in previous studies were considered. The fiber volume fraction was varied from 0.3 to 0.7 and equation 2, 15, 16 and 19 were considered for further evaluation. The current basis is centered on micromechanics-based approach and the authors should proceed with further symptomatic work on various models such as the generalized method of cell approach, three-phase MOM and residual strength and stiffness models for the fatigue damage modeling in composite materials. However, readers are strongly advised to refer to references [66], [67], [68], [69], [70], [71] for micro-scale and [72], [73], [74], [75] for nano-scale effects of the fiber-matrix interface.

Figure 10 shows the behavioral change in the elastic coefficient of stiffness compliance tensor $\left(C_{11}\right)$ with the varying volume fraction of E-glass fiber. It was observed that the optimum volume fraction of fiber $\left(\mathrm{V}_{\mathrm{f}}=\right.$ 0.45 to 0.65 ) is anticipated to have identical appraisals for M-T and the MOM approach. Thus, it is revealed in negligible effects of the fiber-matrix interface on elastic coefficient $\left(C_{11}\right)$.

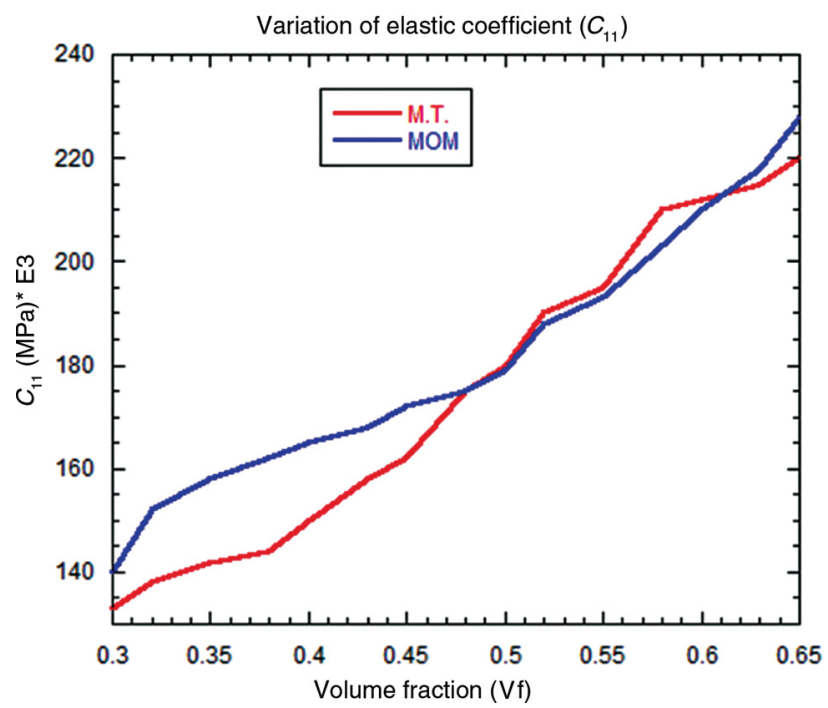

Figure 10: Variation of elastic coefficient $\left(C_{11}\right)$ against the varying E-glass fiber volume fraction.

Variation of elastic coefficient $\left(C_{12}\right)$ with varying fiber volume fraction can be observed in Figure 11 . It could be anticipated that M-T method dominates over the MOM approach and values of the elastic coefficient $\left(C_{12}\right)$ predicted to be higher at higher volume fraction. This develops a new insight of the improved fiber-matrix interface. A similar trend was observed for the estimation of the elastic coefficient $\left(C_{13}\right)$ as the composite material under investigation in this work is orthotropic. This also gives clear cut evidence of the symmetry of the stress tensor. The values of elastic coefficient $\left(C_{22}\right)$ and $\left(C_{33}\right)$ are found to be identical due to symmetry about the axis and are presented in Figure 12. However, Figure 13 shows the large variation between values of elastic coefficient $\left(C_{23}\right)$ estimated by the M-T method and the MOM approach. 


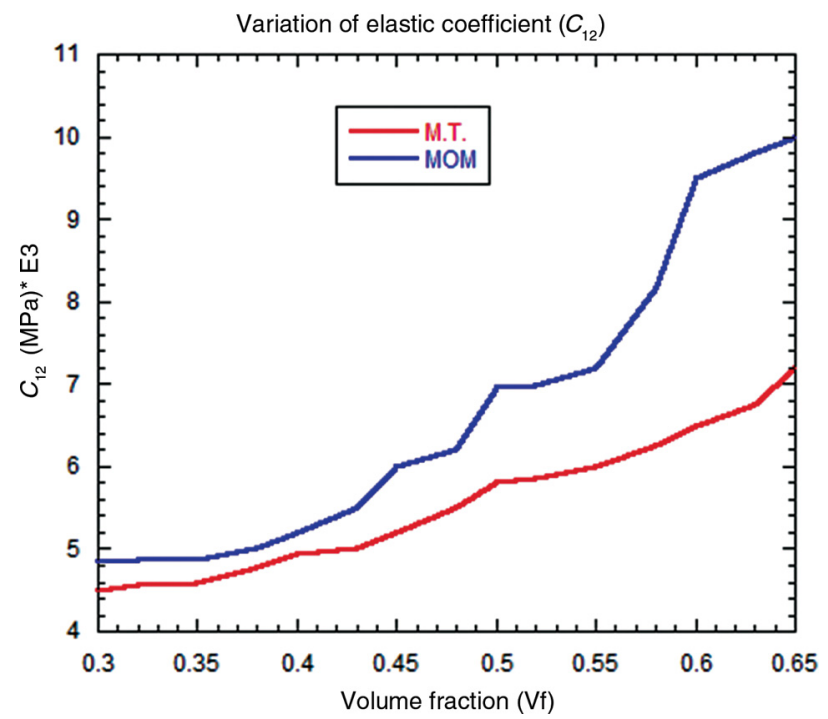

Figure 11: Variation of elastic coefficient $\left(C_{12}\right)$ against the varying E-glass fiber volume fraction.

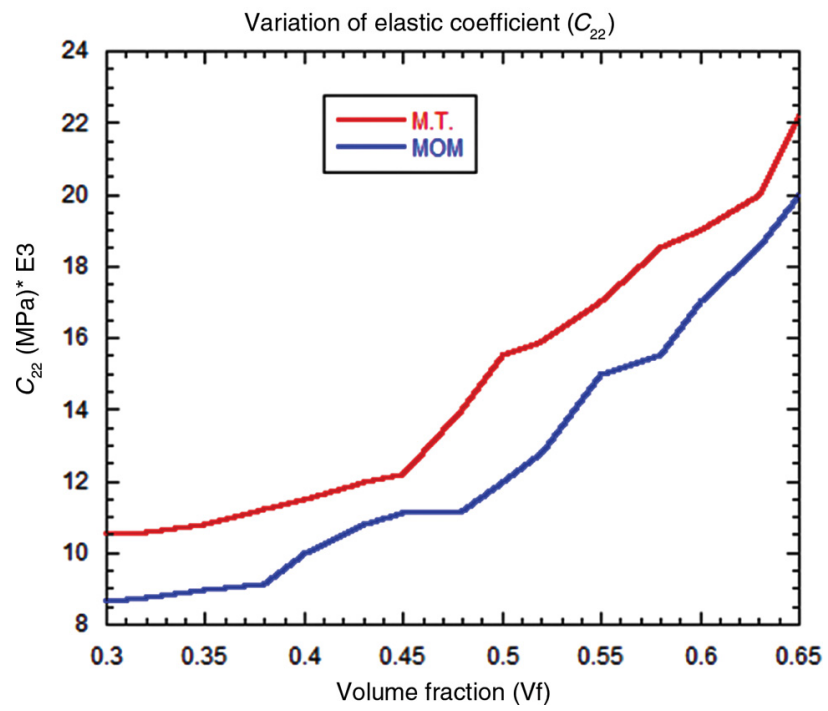

Figure 12: Variation of elastic coefficient $\left(C_{22}\right)$ against the varying E-glass fiber volume fraction.

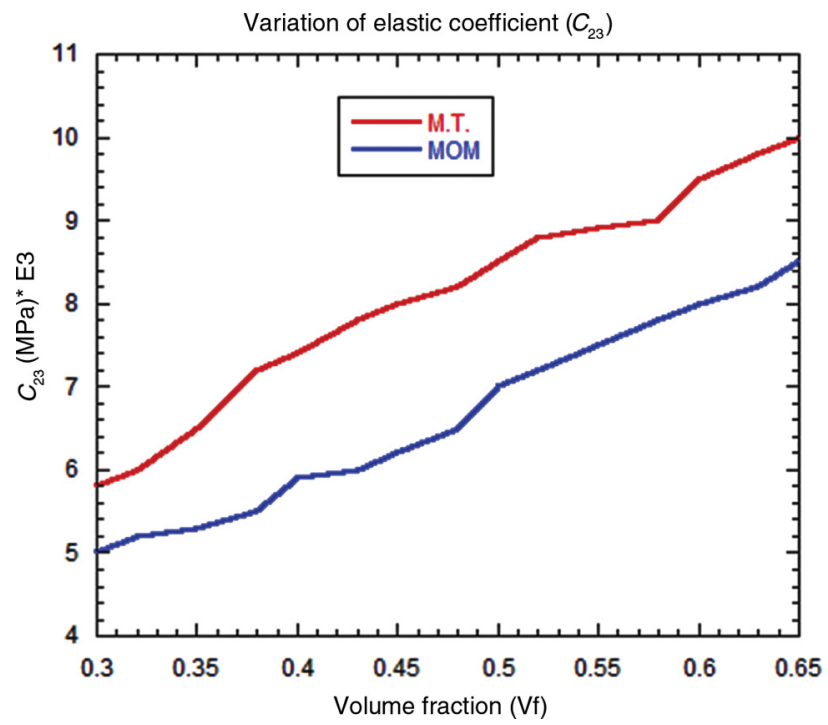

Figure 13: Variation of elastic coefficient $\left(C_{23}\right)$ against the varying E-glass fiber volume fraction.

It is evident from Figure 10-Figure 13 that the M-T method yields slightly more values of elastic coefficient at higher values of the fiber volume fraction. However, this above approach is not adequate to determine the actual 
behavioral change at fiber-matrix interface perhaps it is contingent that further evaluation of elastic properties could be carried out by incorporating the effects of three-phase M-T and the MOM approach.

\subsection{FE analysis}

In this section the tensile test results obtained through the finite-element model of coupon-shaped tensile test specimens are presented. The model was created in ANSYS APDL (parametric development language) package 18.2. A shell 63 element assuming the plane strain condition was used for modeling the tensile test specimen and all the elastic properties were incorporated (refer to section 2.4). A free quadrilateral meshing was used for discretization, and mesh refinement over the area was done to concentrate on elements formed on edges. A typical set of convergence values of 1E-04 having a mesh tolerance of $1 \mathrm{E}-03$ was used to secure accuracy in results. Modeling of the tensile specimens ensures the ASTM D638 course of action. In lieu of boundary conditions, the lower end was arrested by all the degrees of freedom while upper end was prevented in the $U_{y}$ $\left(\mathrm{U}_{\mathrm{y}}=0\right)$ direction so that specimen cannot move horizontally.

Figure 14 illustrates the typical deformation behavior of the tensile test specimen at the applied load equivalent to 600 bar pressure.

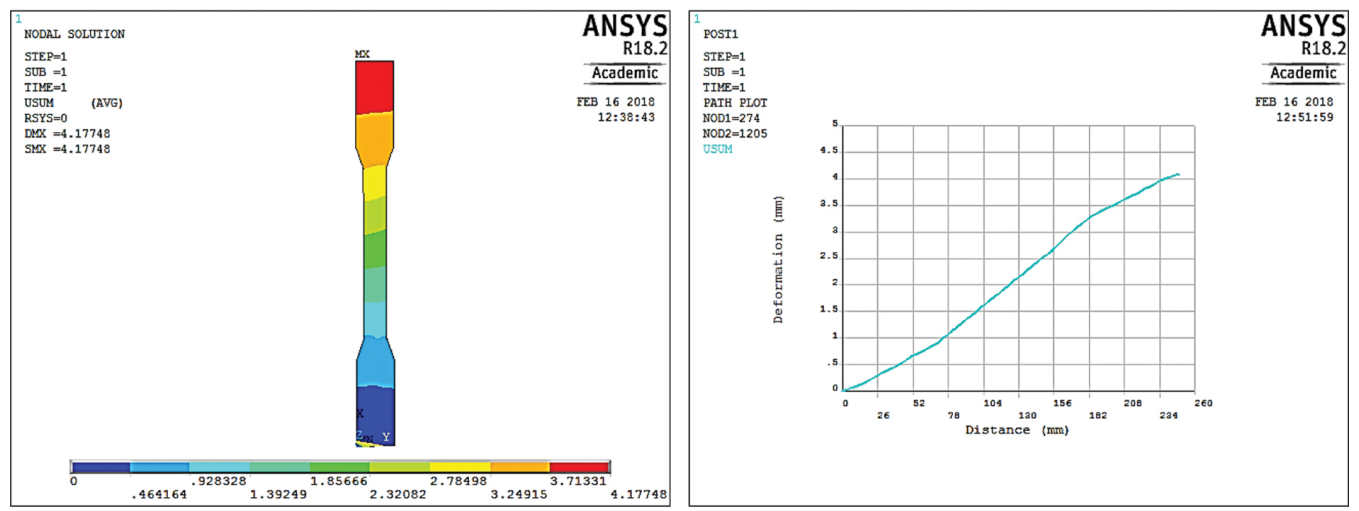

Figure 14: Deformation in a coupon-shaped tensile test specimen obtained by FE analysis.

It is very evident that, the deformation along the specimen more on upper end shows the gradual increase in the nodal variation. This is in agreement with the results obtained in the tensile test experimentally. Variation in von-Mises stresses and strains can be seen in Figure 15 and Figure 16, which are shown in the necking phenomenon after a permissible amount applied load. The maximum breaking load observed experimentally was $14.13 \mathrm{kN}$ approximately and could be attributed to the results obtained through FE analysis. It is worth mentioning here that only the uniaxial effects were considered in the current exercise, however, in future endeavors an attempt could be made to consider the tensile test effects involving thickness stresses.

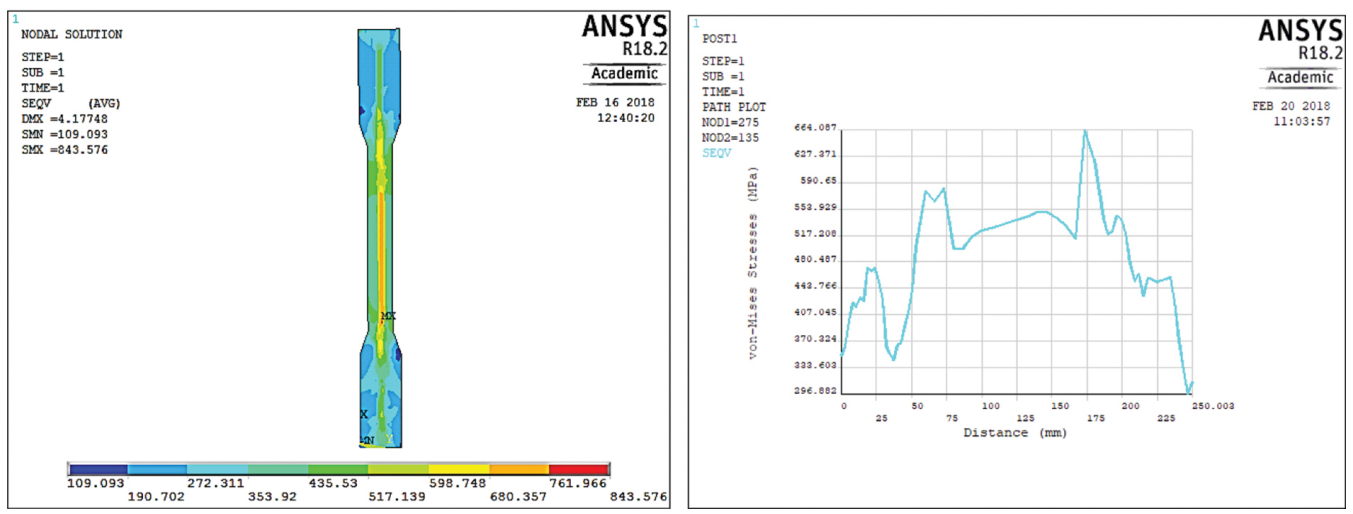

Figure 15: Equivalent von-Mises stresses obtained by FE analysis on a tensile test specimen. 


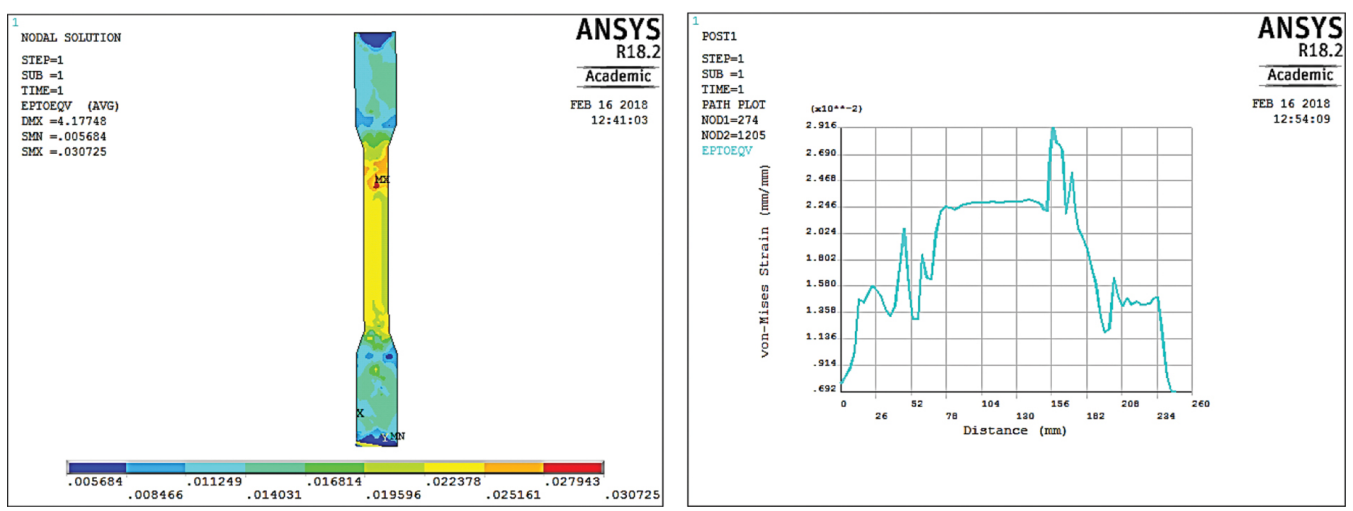

Figure 16: Equivalent von-Mises strain obtained by FE analysis on a tensile test specimen.

It was also observed that the tensile test response for the pressurized samples of these composites was slightly increased as they have shown a greater tendency in breaking loads and this is presented in Figure 17. The analytically obtained stress-strain response slightly overestimates the experimental values. It was also found that there was increase in the yield strength of these composite as a function of the hydrostatic pressure and this estimate agreed well with past studies [76]. Table 4 shows the tensile test response of a coupon-shaped composite specimen measured experimentally and analytically,

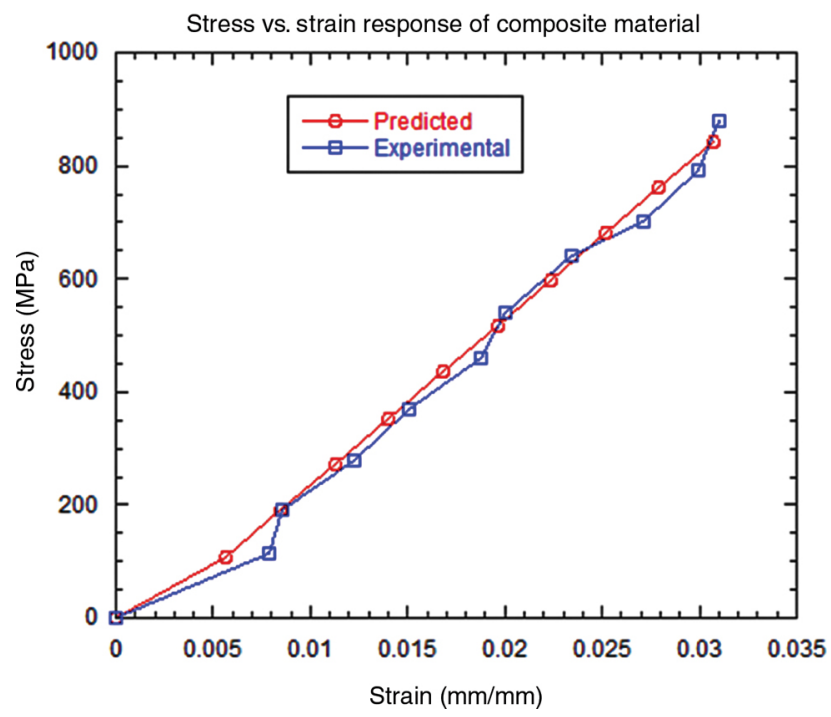

Figure 17: Stress-strain response of composite materials - experimental and predicted.

Table 4: Tensile test response of an E-glass fiber polymer matrix composite (experimental and analytical).

\begin{tabular}{lrr}
\hline Entity & Experimental & Analytical (FE analysis) \\
\hline Deformation $(\mathrm{mm})$ & 4.66 & 4.17 \\
von-Mises stresses $(\mathrm{MPa})$ & 822.65 & 843.526 \\
von-Mises strain $(\mathrm{mm} / \mathrm{mm})$ & 0.00327 & 0.00307 \\
Tensile modulus $(\mathrm{GPa})$ & 251.574 & 274.764 \\
\hline
\end{tabular}

However, it can be assumed that this behavioral change in the mechanical properties of composites no longer remains constant but could be observed as a function of the applied hydrostatic pressure. The behavioral change in elastic and shear modulus has been envisaged in past literature. The basis for the previous observation can be extracted from the notable work done on the mechanical behavior of composites under large hydrostatic pressure by Kathavate et al. [77]. These current estimates are based on the application of composite materials from the marine and aerospace perspectives. However, readers are advised to read references [78], [79], [80], [81], [82], [83], [84], [85], [86], [87], [88], [89], [90], [91], [92] for further studies on damage behavior of composite under hydrostatic pressure. 


\section{Conclusions}

The present work explored the mechanical behavior of an epoxy E-glass fiber composite subjected to high pressure for marine applications having a special emphasis on the experimental and computational approach. A series of tensile tests were carried out for unpressurized and pressurized samples (up to 600 bar) for different hardener-epoxy resin ratios in conjunction with gel-time studies. It was observed from the experiments that the tensile test response of these composites is strongly dependent on the types of microstructural damage produced by underwater pressure. Micromechanics-based constitutive laws were implemented and potent estimation of the elastic coefficients was made to form a compliance matrix. Further FE analysis was also carried out in concurrence with experimental observations. It was found that these series of virtual tests were not adequate to predict the response of these composites and the behavior of the fiber-matrix interphase, therefore, quantitatively internal damage has been visualized using SEM studies. Based on the aforementioned observations, major verdicts of the current exercise are as follows;

- A steep increase in normalized stiffness was observed as a function of hydrostatic pressure when these composite were deployed at high pressure.

- The gel time studies reveal the polarizability of an epoxy resin-hardener matrix which subsequently affects the performance of the composites.

- SEM studies are reflected in the microstructural damage and can be attributed to interface debonding and matrix cracking.

- Significant improvement was observed in the mechanical properties of these composites when pressurized up to 600 bar.

- A micromechanics-based approach shows the estimation of elastic coefficient of stiffness compliance matrix and helps in evaluating the higher order tensors in constitutive equations and nucleation and growth of damage during simulation can be easily traced out using computational micromechanics.

- The M-T approach seems to be promising over the MOM approach as it exposes higher values of elastic coefficient at higher volume fractions.

- This micromechanics-based modeling strategy developed in this work is capable of determining effective elastic properties of these composites.

These studies are not circumscribed but may include exploration of additional debonding properties and the viscoelastic behavior for a realistic approach. Strain-rate dependent studies could be an additional advantage [93]. Nevertheless this would make it possible to have an unbiased understanding of the effect of triaxial loading and the true internal damage would have a direct relation to the properties, irrespective of how the damage was caused.

\section{Future advances and challenges}

The framework proposed here demonstrates the need of virtual testing of mechanical behavior of composite materials and structures for marine and aerospace applications in future. Though there are some gaps in multiscale modeling, but the overall aforementioned work is robust and has already shown its ability to attempt the high-fidelity tests on composite materials under high pressure with varying multiaxial loading conditions.

Future developments and challenges in the area of multiscale modeling are anticipated to incorporate the multifunctional properties. As FRP are becoming reasonable enhanced by auto-clave and the hand layup process, their use in structural components has spread in many marine and aerospace industries.

However, it has been observed that there is hindrance in the physical properties of composite materials (thermal conductivity, moisture absorption and fire resistance) which limits their use. Thus, these issues can be overcome by modification in the matrix (addition of fillers such as clays, carbon nanotubes and nanofibers as well as graphene). One can also look for the effect of waviness of carbon nanotubes for the effective estimation of thermoelastic response of the FRPs. Several studies have reported the thermal and electrical response of these multifunctional nanocomposites which proposes high electrical conductivity, thermal stability and electromagnetic interference shielding [94], [95], [96], [97], [98], [99], [100].

From the virtual testing viewpoint, molecular dynamics (MD) simulations can help to a great extent in the evaluation of the mechanical and functional properties of polymers at the nanometer scale. The extent of MD 
simulation is anticipated to have evolution of set of atoms under external agencies (stress, temperature, pressure and electric field). In past studies, it was observed that MD simulations could help to compute structural and functional properties of cross linked polymers [101], [102].

In conclusion, it is necessary to have a unified multiscale framework for virtual composite testing. Development of integrated design strategy based on several parameters is also an added advantage to aforementioned procedure, so that FRP composites can be designed and optimized in silico (expressions performed via computer simulations) before they are actually manufactured. However, readers are asked to refer to [103], [104], [105], [106], [107], [108], [109], [110] for further information and definitions.

\section{Acknowledgment}

The authors acknowledge their sincere thanks to the Ministry of Earth Sciences, Government of India. We are indebted to Dr. M.A. Atmanand, Director, National Institute of Ocean Technology, Chenna. The authors would also like to extend their gratitude to Dr. G.A. Ramadass, Scientist-G and Group Head, National Institute of Ocean Technology, Chennai, and are thankful to the management of the College of Engineering, Anna University, Guindy, Chennai for providing assistance for microstructural evaluation tests and other facilities. The constant support from Prof. A.S. Adkine, Department of Mechanical Engineering, Shreeyash College of Engineering and Technology, Aurangabad is also appreciated.

Conflict of Interest: The author(s) declared no potential conflicts of interest with respect to the research, authorship, and/or publication of this article.

Funding: The author(s) have received financial support for this research from National Institute of Ocean Technology, Chennai 600100 (under Ministry of Earth Sciences, Government of India) and it has been acknowledged.

\section{References}

[1] Seica MV, Packer ]A. Compos. Struct. 2007, 80, 440-450.

[2] Hollaway L. Handbook of Polymer Composites for Engineers. $1^{\text {st }}$ Edition, Woodhead Publishing Limited: Cambridge, UK, 1994.

[3] Hollaway L, Head PR. Advanced Polymer Composites and Polymers in the Civil Infrastructure. $1^{\text {st }}$ Edition, Elsevier: Oxford, UK, 2001.

[4] Reinhart T]. In: Peters ST, ed. Handbook of Composites. $2^{\text {nd }}$ Edition, Chapman and Hall: London, UK, 1998.

[5] Donadon MV, Iannucci L, Falzon BC, Hodgkinson JM, De Almeida SFM. Compos. Struct. 2008, 86, 1232-1252.

[6] Tenchev RT, Falzon BC. Finite Elem. Anal. Des. 2006, 42, 698-708.

[7] McCullough RL. Delaware Composite Design Encyclopedia-Volume 2: Micromechanical Materials Modeling, Technomic: Lancater, PA, 1990.

[8] Voigt W. Ann. Phys. 1889, 274, 573.

[9] Reuss A. J. Appl. Math. Mech. 1929, 9, 49.

[10] Hill R. Proc. Phys. Soc. 1952, A65, 349-354.

[11] Hashin Z, Shtrikman S. J. Mech. Phys. Solids. 1963, 11, 127-140.

[12] Li C, Chou TW. Int. J. Solids Struct. 2003, 40, 2487-2499.

[13] Treacy MM], Ebbesen TW, Gibson JM. Nature 1996, 381, 678-680.

[14] Llorca ], Gonzalez C, Molina-Aldareguia M, Segurad ], Seltzer R, Sket F, Rodriguez M, Sadaba S, Munoz R, Canal LP. Adv. Mater. 2011, 23, 5130-5147.

[15] Miner MA. J. Appl. Mech. 1945, 12, 159-164.

[16] Revuelta D, Miravete A. Int Appl Mech. 2002, 38 (2), 121-134.

[17] Hashin Z, Rotem A. J. Comp. Mater. 1973, 7, 448-464.

[18] Awerbush ], Hahn HT. In: Fatigue of Fibrous Composite Materials, ASTM STP 723, American Society for Texting Materials, 1981, $243-273$.

[19] Hashin Z. ASME]. Appl. Mech. 1980, 47, 329-334.

[20] Hill R. J. Mech. Phys. Solids. 1965, 13, 189-198.

[21] Chamis CC, Sendeckyj CP. J. Compos. Mater. 1968, 2, 332-358.

[22] Aboudi ]. Mechanics of Composite Materials: A Unified Micromechanical Approach. $1^{\text {st }}$ Edition, Elsevier: Amsterdam, Netherlands, 1991.

[23] Tsai JL, Tzeng SH, Chiu YT. Compos. Part B-Eng. 2010, 41, 106-115.

[24] Shen L, Li ]. Phys. Rev. B. 2004, 69, 045414.

[25] Yang B], Ha SK, Pyo SH, Lee HK. Compos. Part B-Eng. 2014, 62, 159-166.

[26] Yanase K, Moriyama S, Ju JW. Acta. Mech. 2013, 224, 1351-1364.

[27] Zare Y. Mech. Mater. 2015, 85, 1-6.

[28] Hill R. J. Mech. Phys. Solids. 1965, 13, 213-222.

[29] Mori T, Tanaka K. Acta Metall. 1973, 21, 571-574.

[30] Weng C]. Int. J. Eng. Sci. 1984, 22, 845-856. 
[31] ]u JW, Chen TM. Acta Mech. 1994, 103, 103-121.

[32] Ju JW, Chen TM. Acta Mech. 1994, 103, 123-144.

[33] Cartie D, Davies P, Peleau M, Partidge IK. Compos. Part B-Eng. 2006, 37, 292-300.

[34] Assarar M, Scida D, Mahi A El, Poilane C, Ayad R. Mater. Des. 2011, 32, 788-795.

[35] Chow CPL, Xing XS, Li RKY. Compos. Sci. Technol. 2007, 67, 306-313.

[36] Ju JW, Zhang XD. Int. J. Solids Struct. 1998, 35, 941-960.

[37] Ju JW, Zhang XD. Int. J. Solids Struct. 2001, 38, 4045-4069.

[38] Ju JW, Sun LZ. Int. J. Solids Struct. 2001, 38, 183-201.

[39] Sun LZ, Ju JW. Int. J. Solids Struct. 2001, 38, 203-225.

[40] Sun LZ, Ju JW. ASME]. Appl. Mech. 2004, 71, 774-785.

[41] Ju JW, Yanase K. Acta Mech. 2010, 215, 135-153.

[42] Ju JW, Yanase K. Acta Mech. 2011, 216, 87-103.

[43] Barai P, Weng C]. Int. J. Plast. 2011, 27, 539-559.

[44] ASTM D638, Standard Test Method for Tensile Properties of Plastics, 2010.

[45] Halpin JC, Kardos ]L. Polym. Eng. Sci. 1976, 16 (5), 344-352.

[46] Ponte Castaneda P, Suquet P. Adv. Appl. Mech. 1998, 34, 171-302.

[47] Mortensen A, Llorca ]. Annu. Rev. Mater. Res. 2010, 40, 243-270.

[48] Ladeveze P, Le Dantec E. Compos Sci. Technol. 1992, 43, 257-267.

[49] Matzenmiller A, Lubliner ], Taylor RL. Mech. Mater. 1995, 20, 125-152.

[50] Chaboche ]L, Kruch S, Maire JF, Pottier T. Int. J. Plast. 2001, 17, 411-439.

[51] Barbero E], Devivo L. J. Damage Mech. 2001, 10, 73-93.

[52] Ladeveze P, Lubineau G. Compos. Sci. Technol. 2001, 61, 2149-2158.

[53] Maimi P, Camanho PP, Mayugo ]A, Davila CC. Mech. Mater. 2007, 39, 897-908.

[54] Maimi P, Camanho PP, Mayugo ]A, Davila CG. Mech. Mater. 2007, 39, 909-917.

[55] Laurin F, Carrere N, Huchette C, Maire J-F. J. Compos. Mater. 2012, 47 (20-21), 2713-2747.

[56] Camanho P, Maimi P, Davila CC. Compos. Sci. Technol. 2007, 67 (13), 2715-2727.

[57] Maimi P, Camanho PP, Mayugo ]A. J. Compos. Mater. 2008, 42 (25), 2717-2745.

[58] David V, Ladeveze P, Lubineau C. Compos. Sci. Technol. 2009, 69, 1364-1371.

[59] Tsai SW. Strength Characteristics of Composite Materials. NASA CR-224 (A Report), 1965.

[60] Hill R. Proc. Royal Sco. Series A. 1948, 193, 281.

[61] Benveniste Y, Dvorak C]. J. Mech. Phys. Solids 1992, 40, 1295-1312.

[62] Wacker C, Bledzki AK, Chate A. Compos. Part A. 1998, 29A, 619-626.

[63] Smith WA, Auld BA. IEEE Trans. Ultrason. Ferroelectr. Freq. Control. 1991, 38, 40-47.

[64] Benveniste Y. Mech. Mater. 1987, 6, 147-157.

[65] Eshelby JD. Phys. Eng. Sci. 1957, 62, 376-396.

[66] Chouchaoui CS, Benzeggagh ML. Compos. Sci. Technol. 1997, 57, 617-622.

[67] Ji XL, Jing JK, Jiang W, Jiang BZ. Polym. Eng. Sci. 2002, 42, 983-993.

[68] Rafiee R, Rabczuk T, Pourazizi R, Zhao ], Zhang Y. Adv. Mater. Sci. Eng. 2013; Article Id-183026.

[70] Ansari R, Hassanzadeh-Agdham MK, Darvizeh A. Proc. Inst. Mech. Eng. Part L: ] Mater. Des. Appl. 2016, 1-11.

[71] Aboudi ], Arnold SM, Bednarcyk BA. Micromechanics of Composite Materials: A Ceneralized Multiscale Analysis Approach. 1 $^{\text {st }}$ Edition, Butterworth-Heinemann Ltd.: Oxford OX, 2012.

[72] Ansari R, Hassanzadeh-Agdham MK, Darvizeh A. Compos. Part A. 2017, 96, 110-121.

[73] Ansari R, Hassanzadeh-Agdham MK. Meccanica 2017, 52, 1625-1640.

[74] Hammerand DC, Seidel CD, Lagoudas DC. Mech. Adv. Mater. Struct. 2007, 14, 277-294.

[75] Esteva M, Spanos PD. J. Mech. Mater. Struct. 2009, 4, 887-900.

[76] Davies P, Rajapakse YS. Durability of Composites in Marine Environment, Springer, ISBN: 978-94-007-7416-2, 2014.

[77] Kathavate VS, Amudha K, Ramesh NR, Ramadass CA. Mater Today Proc. (Article in Press).

[78] Kaminski M, Laurin F, Maire JF, Rakotoarisoa C, Hemon E. J. Aerosp. Lab. 2015, 9, 1-12.

[79] Pandita SD, Verpoest I. Compos. Struct. 2004, 64 (2), 199-209.

[80] Bathias C. Int. ]. Fatigue 2006, 28, 1094-1099.

[81] Konur O, Matthews FL. Composites 1989, 20, 317-328.

[82] Patel DK, Waas AM. Philos. Trans. A Math. Phys. Eng. Sci. 2016, 374, 1-31.

[83] Lee HK, Kim BR. Compos. Sci. Technol. 2007, 67, 2221-2230.

[84] Guo S]. Compos. Struct. 2007, 80, 1-9.

[85] Sevenois RDB, Paepegem VW. Appl. Mech. Rev. ASME. 2015, 68, 1-12.

[86] Quaresimin M, Ricotta M. Fatigue Response and Damage Evaluation in 2-D Textile Composites, Chapter 9. Fatigue of Textile Composite, Wood Head Publishing-Composite Science and Engineering; 193-218.

[87] Carvelli V, Lomov SV. Fatigue Damage Evaluation in 3-D Textile Composites, Chapter 10. Fatigue of Textile Composite, Wood Head PublishingComposite Science and Engineering; 223-251.

[88] Mouritz AP. Fatigue of 3-D Textile Reinforced Composite, Chapter 11. Fatigue of Textile Composite, Wood Head Publishing-Composite Science and Engineering, 55-269.

[89] Nelson EE, Hansen AC, Mayes ]S. J. Compos. Mater. 2012, 46 (19-20), 2461-2483.

[90] Bridgeman PW. ]. Appl. Phys. 1952, 24, 1-52.

[91] Messager T, Pyrz M, Gineste B, Chauchot P. Compos. Struct. 2002, 58, 529-537. 
[92] Brown TL, Hyper MW. Am. Soc. Testing Mater. 1994, 78-96.

[93] Yang B], Kim BR, Lee HK. Compos. Struct. 2012, 94, 1420-1429.

[94] Gilman JW. Appl. Clay Sci. 1999, 15 (1-2), 31-49.

[95] Mohammad M, Ki W. Macromolecules 2006, 39, 5194-5205.

[96] Wei C, Srivastva D, Cho K. Nano Lett. 2002, 2, 647-650.

[97] Dasari A, Yu ZZ, Mai YW, Cai G, Song H. Polymer 2009, 50, 1577-1587.

[98] Dasari A, Yu ZZ, Mai YW. Polymer 2009, 50, 4112-4121.

[99] Kyrylyuk AV, Hermant MC, Schilling T, Klumperman B, Koning CE, Van der Schoot P. Nat. Nanotechnol. 2011, 6, 364-369.

[100] Kuilla T, Bhadra S, Yao D, Kim NH, Bose S, Lee ]H. Prog. Polym. Sci. 2010, 35, 1350-1375.

[101] Zeng QH, Yu AB, Lu GQ. Prog. Polym. Sci. 2008, 33, 191-269.

[102] Yarovsky L, Evans E. Polymer. 2002, 43, 963-969.

[103] Ansari R, Hassanzadeh Aghdam MK. Trans. Phenom. Nano Micro Scales. 2016, 4 (2), 1-8.

[104] Mouritz AP. Composites 1995, 26 (1), 3-9.

[105] Narayanaswami R, Adelman H. J. Compos. Mater. 1977, 11, 366

[106] Chen W, Cheng F, Lu M. Polymer Testing: Test Method 2002, 21, 113-121.

[107] Ling L, Zhengming H. Acta Mechanica Solida Sinica 2014, 27 (3), 234-244.

[108] Pyo SH, Lee HK. Comput. Model. Eng. Sci. 2009, 40, 271-305.

[109] Park SM, Yang B], Kim BR, Ha SK, Lee HK. Int. J. Damage Mech. 2017, 26 (2), 358-376.

[110] Senthilnathan K, Hiremath CP, Naik NK, Guha A, Tewari A. Compos. Part A-Eng. 2017, 100, 118-127. 